Check for updates

Cite this: RSC Adv., 2020, 10, 18655

\section{A two-enzyme cascade reaction consisting of two reaction pathways. Studies in bulk solution for understanding the performance of a flow-through device with immobilised enzymes $\uparrow$}

\author{
Nicolas Ghéczy, (D) $\ddagger^{a}$ Kai Sasaki, (ID $\ddagger \S^{a}$ Makoto Yoshimoto, (DD ab Sajad Pour- \\ Esmaeil, (D) q ${ }^{a}$ Martin Kröger, (ID ${ }^{c}$ Pasquale Stano (D) ${ }^{d}$ and Peter Walde (D) *a
}

Enzyme-catalysed cascade reactions in flow-through systems with immobilised enzymes currently are of great interest for exploring their potential for biosynthetic and bioanalytical applications. Basic studies in this field often aim at understanding the stability of the immobilised enzymes and their catalytic performance, for example, in terms of yield of a desired reaction product, analyte detection limit, enzyme stability or reaction reproducibility. In the work presented, a cascade reaction involving the two enzymes bovine carbonic anhydrase (BCA) and horseradish peroxidase (HRP) - with hydrogen peroxide $\left(\mathrm{H}_{2} \mathrm{O}_{2}\right)$ as HRP "activator" - was first investigated in great detail in bulk solution at $\mathrm{pH}=7.2$. The reaction studied is the hydrolysis and oxidation of $2^{\prime}, 7^{\prime}$-dichlorodihydrofluorescein diacetate (DCFH $\left.2-D A\right)$ to $2^{\prime}, 7^{\prime}$ dichlorofluorescein (DCF), which was found to proceed along two reaction pathways. This two-enzyme cascade reaction was then applied for analysing the performance of BCA and HRP immobilised in glass fiber filters which were placed inside a filter holder device through which a $D C F H_{2}-D A / H_{2} \mathrm{O}_{2}$ substrate solution was pumped. Comparison was made between (i) co-immobilised and (ii) sequentially immobilised enzymes (BCA first, HRP second). Significant differences for the two arrangements in terms of measured product yield (DCF) could be explained based on quantitative UV/vis absorption measurements carried out in bulk solution. We found that the lower DCF yield observed for sequentially immobilised enzymes originates from a change in one of the two possible reaction pathways due to enzyme separation, which was not the case for enzymes that were co-immobilised (or simultaneously present in the bulk solution experiments). The higher DCF yield observed for co-immobilised enzymes did not originate from a molecular proximity effect (no increased oxidation compared to sequential immobilisation).
Received 7th February 2020 Accepted 29th April 2020 DOI: 10.1039/dOra01204a rsc.li/rsc-advances

\section{Introduction}

The study of enzymatic cascade reactions taking place inside dispersed compartments or on solid surfaces is currently attracting a lot of attention. ${ }^{\mathbf{1 - 1 9}}$ There are at least two reasons for the interest in these systems: (i) the possible mimicking of enzymatic cascade reactions as they occur in vivo towards a better understanding of the efficiency of metabolic reactions; and (ii) the development of selective, stable and reusable bioanalytical and biosynthetic devices. Well-studied bioanalytical systems are two-enzyme cascade reactions, i.e., coupled enzyme assays involving an oxidase and a peroxidase. Examples are glucose oxidase (abbreviated as GOD or GOx) and horseradish peroxidase (HRP) for the quantification of $\mathrm{D}^{-g l u c o s e},{ }^{20,21}$ or three-enzyme cascade reactions involving $\beta$-galactosidase $(\beta$ Gal), GOD, and HRP for the quantification of lactose. ${ }^{20,22}$ In both cases, quantification of the analyte (D-glucose or lactose) is achieved through a determination of hydrogen peroxide $\left(\mathrm{H}_{2} \mathrm{O}_{2}\right)$ 
which is formed in stoichiometric amounts as side product in the oxidation of D-glucose to glucono- $\delta$-lactone with $\mathrm{GOD} / \mathrm{O}_{2}$. The formed $\mathrm{H}_{2} \mathrm{O}_{2}$, which is the key intermediate that links the two reactions, rapidly oxidises HRP which in turn oxidises a chosen, suitable reducing substrate that is added. This reducing substrate often is selected such that its one-electron oxidation (or possible rapid follow-up reactions) can be monitored spectrophotometrically. Well known examples are ABTS ${ }^{2-}\left(\mathrm{NH}_{4}{ }^{+}\right)_{2} \quad$ (2,2'-azino-bis(3-ethylbenzothiazoline-6sulfonic acid)diammonium salt), ${ }^{23}$ TMB $\left(3,3^{\prime}, 5,5^{\prime}\right.$-tetramethylbenzidine), ${ }^{24}$ or OPD (ortho-phenylenediamine $=1,2$ diaminobenzene). ${ }^{25}$

The work presented consists of two parts. In the first part, we aimed at understanding in detail a two-enzyme cascade reaction in bulk solution at $\mathrm{pH}=7.2$ involving BCA (bovine erythrocyte carbonic anhydrase) and HRP. The substrates used were $2^{\prime}, 7^{\prime}$ dichlorodihydrofluorescein diacetate ( DCFH $_{2}$-DA) and $\mathrm{H}_{2} \mathrm{O}_{2}$ (the results are presented and discussed in Section 3.1.). This cascade reaction differs from the ones mentioned above, and is related to a well-known assay applied in experimental cell physiology to determine the presence of reactive oxygen and nitrogen species (ROS and RNS) inside cells. ${ }^{26-34}$ In that well-known assay, the focus is on determining the presence of ROS or RNS. In the first part of our work, however, the goal was not to apply the cascade reaction to such an assay, but to understand the reaction catalysed by BCA and HRP in order to later understand the behavior of differently immobilized BCA and HRP.

From a mechanistic viewpoint, the cascade reaction we investigated consists of two possible reaction pathways involving more than five different reaction steps, as outlined in detail in the following. In contrast to the conventional oxidaseperoxidase coupled assays, $\mathrm{H}_{2} \mathrm{O}_{2}$ does not play the role of an in situ formed linking intermediate, but is one of the added substrates. The cascade reaction is summarised in Scheme 1 (complete $\mathbf{D C F H}_{2}$-DA hydrolysis before oxidation, as known from literature) and Scheme 2 (simplified representation including oxidation upon partial hydrolysis of $\mathbf{D C F H}_{\mathbf{2}}$-DA, as found in this work). Schemes 1 and 2 include the chemical structures of the compounds dominating at $\mathrm{pH}=7.2$ (see also Fig. S-1, ESI $\dagger$ ).

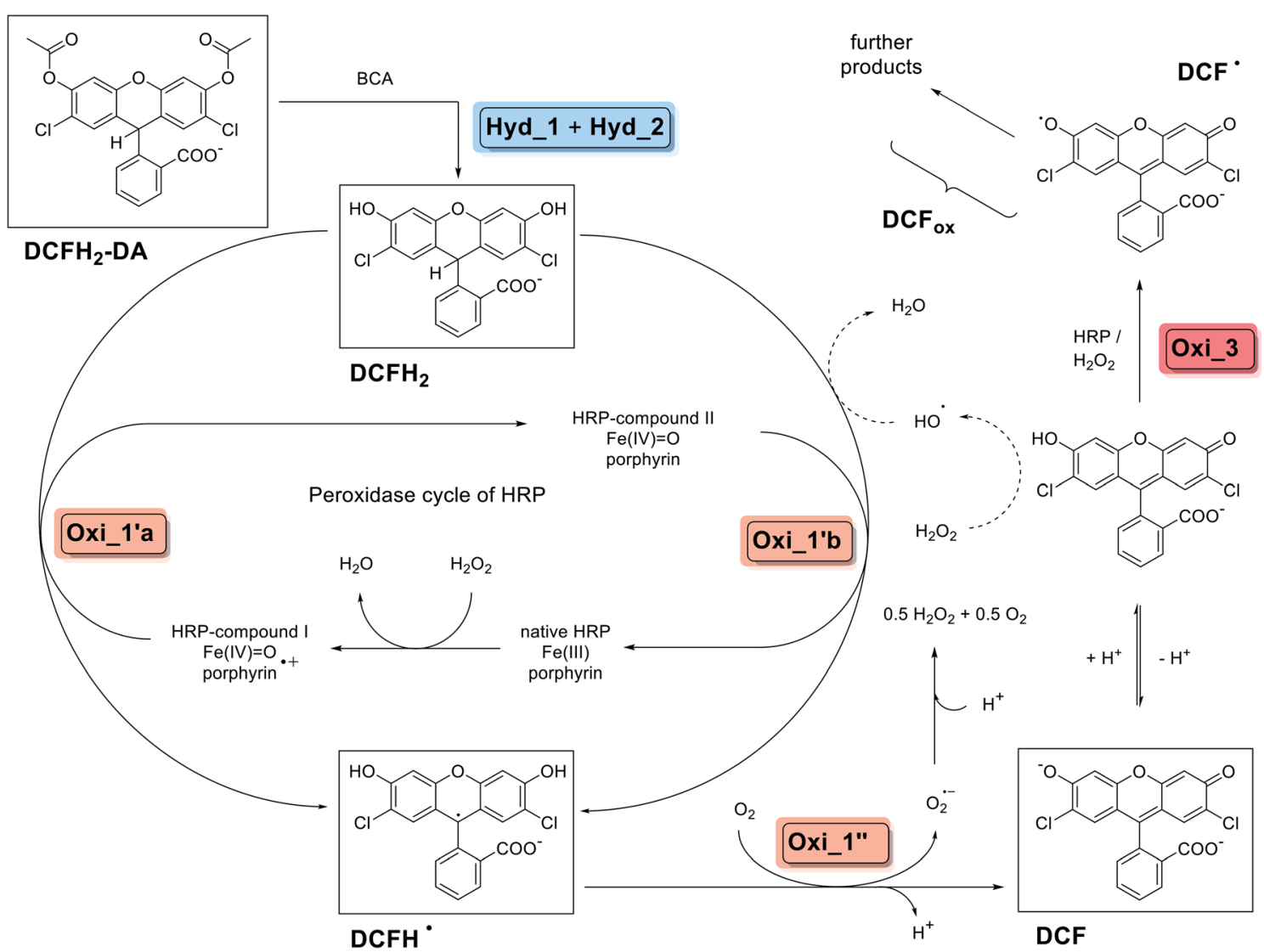

Scheme 1 Overview about the two-enzyme cascade reaction analysed and applied in this work, describing the situation for an initial complete hydrolysis of $\mathrm{DCFH}_{2}-\mathrm{DA}$ to $\mathrm{DCFH} \mathrm{H}_{2}$, followed by oxidation using $\mathrm{HRP} / \mathrm{H}_{2} \mathrm{O}_{2}$ (pathway 1 of Scheme 2). The scheme summarises key findings of a number of previous detailed studies (not using BCA, but other esterases), see for example (Rota et al., 1999) ${ }^{44}$ and (Wardman, 2007). ${ }^{31}$ Steps Hyd_1 and Hyd_2 are the BCA-catalysed hydrolyses of DCFH $2-D A\left(\lambda_{\max }=260 \mathrm{~nm}\right)$ to $\mathrm{DCFH}_{2}\left(\lambda_{\max }=287 \mathrm{~nm}\right)$. Steps Oxi_1'a and Oxi_1'b are the two possible one-electron oxidations of $\mathrm{DCFH}_{2}$ to $\mathrm{DCFH}^{*}$ by HRP-compound I and HRP-compound II, respectively, which are followed by the one-electron oxidation (step Oxi_1") of DCFH' to DCF $\left(\lambda_{\max }=503 \mathrm{~nm}\right.$ ). Step Oxi_3 is the $\mathrm{HRP}_{1} \mathrm{H}_{2} \mathrm{O}_{2}$-catalysed oxidation of DCF to DCF' and possible follow-up reactions (yielding further products, altogether abbreviated as $\mathrm{DCF}_{\mathrm{ox}}$ ). Non-enzymatic formation of hydroxyl radicals ( $\mathrm{HO} \mathrm{O}^{\circ}$ )

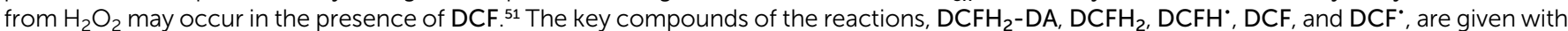
the chemical structures of the dominating species at the $\mathrm{pH}$ conditions of the reaction $(\mathrm{pH}=7.2)$, see text for details. For information about the different acid-base equilibria of $\mathrm{DCFH}_{2}, \mathrm{DCFH}^{\cdot}$ and DCF, see (Wrona and Wardman, 2006) ${ }^{48}$ and Fig. S-1, ESI. $\dagger$ 


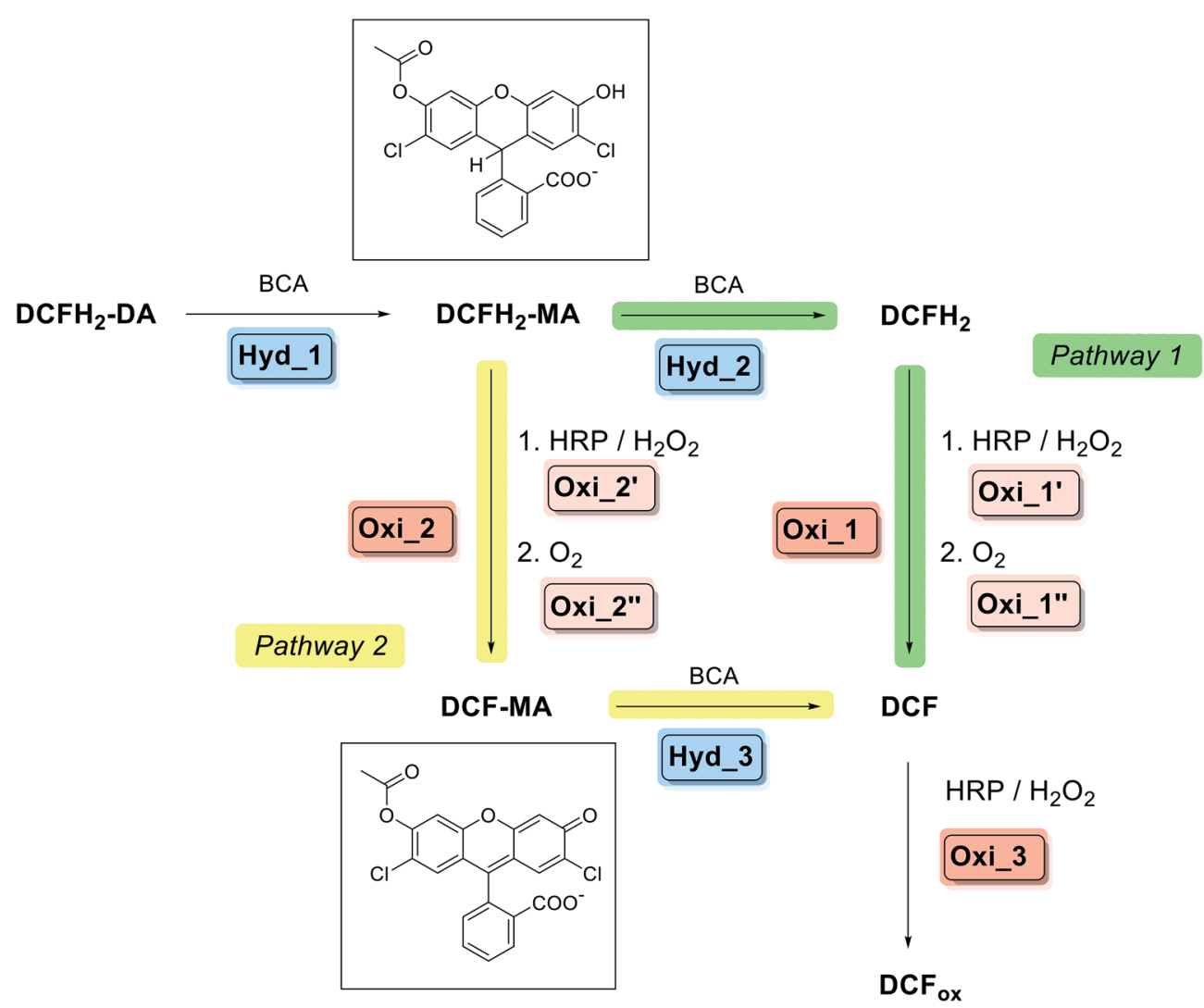

Scheme 2 Overview about pathway 1 and pathway 2 of the two-enzyme cascade reaction analysed and applied in this work; describing the situation for simultaneous addition of BCA and HRP to DCFH $\mathrm{H}_{2}$-DA in the presence of $\mathrm{H}_{2} \mathrm{O}_{2}$ at the beginning. For details of pathway 1 , see Scheme 1: Hyd_1 $\rightarrow$ Hyd_2 $\rightarrow$ Oxi_1 $(\rightarrow$ Oxi_3). In pathway 2, DCFH 2 -MA is oxidised to DCF-MA, followed by hydrolysis to DCF: Hyd_1 $\rightarrow$ Oxi_2 $\rightarrow$ Hyd_3 $(\rightarrow$ Oxi_3). The chemical structures of the two important intermediates DCFH $2-M A$ and DCF-MA are shown. Formation of DCF ox (reaction Oxi_3) only occured to a significant extent in the presence of $\mathrm{HRP}$ and if $\mathrm{H}_{2} \mathrm{O}_{2}$ was present in excess over DCFH $\mathrm{H}_{2}$ as well as $\mathrm{HRP}$ was not rate limiting for the formation of DCF-MA/DCF. The oxidation reactions were faster than the hydrolysis reactions when similar molar concentrations of BCA and HRP were present. For the BCA-catalysed hydrolysis reactions the kinetic efficiency was found in the relation: Hyd_1 > Hyd_3 > Hyd_2 (see later Table S-2, ESI†); while for the HRP-catalysed oxidations, Oxi_1 > Oxi_2 was found (see later Scheme-S1, ESI $\dagger$ ). Experimental data confirmed the expectation that the higher the ratio of BCA to HRP, the higher the contribution from pathway 1; and the lower the reaction time, the higher the contribution from pathway 2 (see later Section 3.1.6.).

DCFH $_{2}$-DA has two (identical) ester bonds, the hydrolysis of both is catalysed by BCA, similar to fluorescein diacetate (the oxidised form of $\mathbf{D C F H}_{2}$-DA) ${ }^{35}$ or 6-carboxyfluorescein diacetate (Fig. S-2, ESI $\dagger$ ). ${ }^{36}$ Upon initial addition of $\mathbf{D C F H}_{2}$-DA, BCA, HRP and $\mathrm{H}_{2} \mathrm{O}_{2}$, the first reaction intermediate obtained from $\mathbf{D C F H} \mathbf{C}^{-}$ DA by the action of BCA, 2', $7^{\prime}$-dichlorodihydrofluorescein monoacetate ( $\mathbf{D C F H}_{2}$-MA), is either hydrolysed by BCA to $2^{\prime}, 7^{\prime}$ dichlorodihydrofluorescein $\left(\mathbf{D C F H}_{2}\right)$ or oxidised by $\mathrm{HRP} / \mathrm{H}_{2} \mathrm{O}_{2}$ to $2^{\prime}, 7^{\prime}$-dichlorofluorescein monoacetate (DCF-MA) (Scheme 2). Hydrolysis of DCF-MA by BCA or oxidation of $\mathbf{D C F H}_{\mathbf{2}}$ by HRP/ $\mathrm{H}_{2} \mathrm{O}_{2}$ yields $2^{\prime}, 7^{\prime}$-dichlorofluorescein (DCF). In the presence of $\mathrm{HRP}$ and $\mathrm{H}_{2} \mathrm{O}_{2}$, DCF may be oxidised further, depending on the experimental conditions; the products obtained are the phenoxyl radical DCF$^{*}$ (Scheme 1) and possibly other oxidation products whose chemical structures are unknown. Any type of oxidised form of DCF is abbreviated as $\mathbf{D C F}_{\mathbf{o x}}$ (Schemes 1 and 2). While $\mathbf{D C F H}_{2}$-DA, $\mathbf{D C F H} \mathbf{H}_{2}$-MA and $\mathbf{D C F H} \mathbf{H}_{\mathbf{2}}$ are colourless and non-fluorescent, DCF has a red colour $\left(\lambda_{\max }=503 \mathrm{~nm}\right)$ and is fluorescent. ${ }^{37,38}$ For the spectroscopic properties of DCF-MA and $\mathbf{D C F}_{\mathbf{o x}}$, see Results and discussion. From a previous study it is known that $\mathbf{D C F}_{\mathbf{o x}}$ has a drastically reduced absorption at $\lambda=$ $503 \mathrm{~nm}$, as compared to DCF, with concomitant decrease in fluorescence. ${ }^{39}$

Overall, the seemingly simple two-enzyme cascade reaction can occur via two pathways (Scheme 2). For pathway 1, $\mathbf{D C F H}_{2}$ DA first undergoes complete hydrolysis to $\mathbf{D C F H} \mathbf{H}_{\mathbf{2}}$, followed by oxidation to $\mathbf{D C F}$ and possibly $\mathbf{D C F}_{\mathbf{o x}}$. The reaction steps are: Hyd_1 $\rightarrow$ Hyd_2 $\rightarrow$ Oxi_1 $(\rightarrow$ Oxi_3). For pathway 2, DCFH 2 -DA is only partially hydrolysed to $\mathbf{D C F H}_{2}$-MA, followed by oxidation to DCF-MA and then hydrolysis to DCF and possibly oxidation to $\mathbf{D C F}_{\mathbf{o x}}$. The reaction steps are: Hyd_1 $\rightarrow$ Oxi_2 $\rightarrow$ Hyd_3 $(\rightarrow$ Oxi_3). Whether the two-enzyme cascade reaction proceeds predominantly via pathway 1 or 2 depends on whether the hydrolysis of $\mathbf{D C F H} \mathbf{H}_{2}$-MA is faster or slower than its oxidation.

Scheme 1 summarises known details from literature concerning pathway 1 , illustrating the situation when an esterase (BCA or a different one) is added in excess over $\mathrm{HRP} / \mathrm{H}_{2} \mathrm{O}_{2}$ (in terms of activity) or before $\mathrm{HRP} / \mathrm{H}_{2} \mathrm{O}_{2}$ to a solution of $\mathbf{D C F H} \mathbf{H}_{2}$-DA so that complete hydrolysis to $\mathbf{D C F H}_{2}$ occurs before oxidation. After oxidation by $\mathrm{HRP} / \mathrm{H}_{2} \mathrm{O}_{2}$, DCF is obtained (via $\mathbf{\text { DCFH}} \mathbf{H}^{\circ}$ as 
short-lived intermediate, see below), indicated as steps Oxi_1' and Oxi_1". Finally, oxidation of DCF to DCF ${ }^{*}$ and to further oxidation products is possible (formation of $\mathbf{D C F}_{\mathbf{o x}}$ ) ${ }^{\mathbf{4 0 - 4 2}}$

Concerning the two-electron oxidation of $\mathbf{D C F H} \mathbf{H}_{2}$ to $\mathbf{D C F}$ (step Oxi_1 in Schemes 1 and 2), it is known from literature that this reaction can take place spontaneously (slow auto-oxidation), ${ }^{43}$ but occurs readily with HRP (or other heme proteins) in the presence of $\mathrm{H}_{2} \mathrm{O}_{2}$ (and $\mathrm{O}_{2}$ ). ${ }^{31,42}$ Detailed previous studies suggest the following mechanism (Scheme 1): ${ }^{\mathbf{3 1 , 4 4}}$ Native HRP is first oxidised by $\mathrm{H}_{2} \mathrm{O}_{2}$ in a two-electron oxidation to yield HRPcompound I. This is the first step of the well-known peroxidase cycle of HRP. ${ }^{4-47} \mathbf{D C F H}_{2}$ is then oxidised by HRP-compound I in a one-electron oxidation to yield DCFH' (Oxi_1'a in Scheme 1). In this reaction, HRP-compound I is reduced to HRP-compound II, which can oxidise an additional molecule of $\mathbf{D C F H}_{2}$ to yield another DCFH' (Oxi_1'b in Scheme 1), whereby HRP-compound II is reduced to HRP. Deprotonation of DCFH $^{\cdot}\left(\mathrm{p} K_{\mathrm{a}} \sim 8.8\right)^{48}$ leads to the formation of $\mathbf{D C F}^{--}$(Fig. S-1, ESI $\dagger$ ). Oxidation of DCFH $^{*} / \mathbf{D C F}^{\cdot-}$ to DCF occurs rapidly with $\mathrm{O}_{2}$, with concomitant formation of the superoxide radical anion, $\mathrm{O}_{2}{ }^{-}$(Oxi_1" in Scheme 1), ${ }^{49}$ which is known to spontaneously dismutate to $\mathrm{O}_{2}$ and $\mathrm{H}_{2} \mathrm{O}_{2}$ (disproportionation reaction: $2 \mathrm{O}_{2}{ }^{--}+2 \mathrm{H}^{+} \rightarrow \mathrm{H}_{2} \mathrm{O}_{2}+$ $\left.\mathrm{O}_{2}\right) \cdot{ }^{50}$ The formed $\mathrm{H}_{2} \mathrm{O}_{2}$ acts as an accelerator of the oxidation of DCFH $_{2}$, and $\mathrm{O}_{2}$ oxidises DCFH $/$ DCF $^{--}$(see above). Finally, it was reported that DCF in the presence of $\mathrm{H}_{2} \mathrm{O}_{2}$ may lead to the formation of hydroxyl radicals, $\mathrm{HO}^{*},{ }^{51}$ which in turn may oxidise peroxidase substrates (e.g., $\mathbf{D C F} \mathbf{H}_{2}$ ), indicated by the dashed arrows in Scheme 1. This type of "peroxidase substrateoxidizing activity" of DCF was demonstrated with $0.4 \mathrm{mM}$ TMB as peroxidase substrate. ${ }^{51}$

Independent from the complexity of the reaction, if the cascade reaction works according to pathway 1 (Scheme 2), DCF is obtained from $\mathbf{D C F H}_{2}$-DA via $\mathbf{D C F H}_{2}$-MA and $\mathbf{D C F H}_{2}$. For pathway 2, $\mathbf{D C F H}_{2}$-MA and DCF-MA are formed as intermediates (Scheme 2). In both cases, formation of $\mathbf{D C F}_{\mathbf{o x}}$ is possible. The determination of the absorption spectra of $\mathbf{D C F H}_{2}$-DA, DCFH $_{2}$-MA, DCFH 2 , DCF-MA, DCF, and DCF $_{\text {ox }}$ within the first part of our work allowed quantifying the composition of the reaction mixture during the course of the reaction and after reaching reaction equilibrium in bulk solution.

After having investigated the reaction in bulk solution, the results obtained were applied in the second part of the work to understand the performance of the two enzymes after they were immobilised and used in a flow-through device (the results are presented and discussed in Sections 3.2. and 3.3.). The enzymes were immobilised in glass fibre filters with a method that was elaborated before for BCA, ${ }^{52}$ and the two filters were placed in a home-made filter holder device for running flow-through reactions. The focus was on a comparison of the outflow in the case of co-immobilised enzymes as compared to sequentially immobilised enzymes.

\section{Materials and methods}

\subsection{Chemicals}

2.1.1. Enzymes. Bovine erythrocyte carbonic anhydrase (BCA, EC 4.2.1.1, cat. number C2624, lot \#SLBR4228 V, $M_{\mathrm{r}} \sim$
$29000, \mathrm{pI}=5.9),{ }^{53,54}$ was obtained from Sigma-Aldrich (molar absorption coefficient at $\lambda=280 \mathrm{~nm}, \varepsilon_{280}$ (BCA) $=$ $\left.56000 \mathrm{M}^{-1} \mathrm{~cm}^{-1}\right) .{ }^{55}$ Horseradish peroxidase isoenzyme C (HRP, EC 1.11.1.7, cat. number PEO-131, grade I, lot 8153665000, RZ $\left.\left(A_{403} / A_{260}\right)=3.0, M_{\mathrm{r}} \sim 44000, \mathrm{pI}=8.8\right)^{47}$ was purchased from Toyobo Enzymes, Japan $\left(\varepsilon_{403}(\mathrm{HRP})=102000 \mathrm{M}^{-1} \mathrm{~cm}^{-1}\right) .{ }^{56,57}$

2.1.2. Buffer solution. If not mentioned else, a $10 \mathrm{mM}$ sodium phosphate buffer solution $(\mathrm{pH}=7.2)$ was used throughout the work, abbreviated as $\mathrm{PB}$. It was prepared from sodium phosphate monobasic $\left(\mathrm{NaH}_{2} \mathrm{PO}_{4}, \geq 99.0 \%\right.$, from Sigma) and either sodium phosphate dibasic $\left(\mathrm{Na}_{2} \mathrm{HPO}_{4}, \geq 99.0 \%\right.$, from Sigma), or by adjustment of the $\mathrm{pH}$ value with a solution of $\mathrm{NaOH}$.

2.1.3. Dendronised polymer. The deprotected second generation dendronised polymer with on average 1000 repeating units, abbreviated as de-PG $2_{1000}\left(\mathrm{PDI}=M_{\mathrm{w}} / M_{\mathrm{n}}=2.4\right)$ was a gift of Dr Daniel Messmer and Prof. A. Dieter Schlüter (ETH Zürich), see (Küchler et al., 2017) ${ }^{58}$ and (Hou et al., 2019) ${ }^{59}$ for details.

2.1.4. Enzyme substrates. $p$-Nitrophenyl acetate ( $p$-NA, $>98 \%$ ) was obtained from TCI (cat. number A0040, lot DAI4M$\left.\mathrm{CR}, M_{\mathrm{r}}=187.15\right), 2^{\prime}, 7^{\prime}$-dichlorodihydrofluorescein diacetate $\left(\right.$ DCFH $_{2}-\mathbf{D A}, \geq 95 \%, \varepsilon_{260}\left(\right.$ DCFH $\left._{2}-\mathbf{D A}\right)=11000 \mathrm{M}^{-1} \mathrm{~cm}^{-1}$, determined in PB) from Cayman Chemical (product 85155, lot 0523494-3, $\left.M_{\mathrm{r}}=487.3\right), 2^{\prime}, 7^{\prime}$-dichlorofluorescein diacetate (DCF-DA, $\geq 95 \%$, product 35845, lot \#BCBV6655, $M_{\mathrm{r}}=485.27$ ) from Sigma-Aldrich, 2,2'-azino-bis(3-ethylbenzothiazoline-6sulfonic acid)diammonium salt $\left(\mathrm{ABTS}^{2-}\left(\mathrm{NH}_{4}{ }^{+}\right)_{2}, \geq 98 \%, \varepsilon_{340}\right.$ $\left.\left(\mathrm{ABTS}^{2-}\right)=36000 \mathrm{M}^{-1} \mathrm{~cm}^{-1}\right)^{23}$ from Sigma-Aldrich (cat. number A1888, lot SLBV3167, $M_{\mathrm{r}}=548.68$ ), and hydrogen peroxide $\left(\mathrm{H}_{2} \mathrm{O}_{2}, 35 \mathrm{wt} \%\right)$ was from Acros Organics (product 202460010, lot A0352305). The molar concentration of $\mathrm{H}_{2} \mathrm{O}_{2}$ in the $35 \mathrm{wt} \%$ solution $(11.7 \mathrm{M})$ was determined spectrophotometrically after dilution with deionised water and using $\varepsilon_{240}$ $\left(\mathrm{H}_{2} \mathrm{O}_{2}\right)=43.6 \mathrm{M}^{-1} \mathrm{~cm}^{-1}$. $^{60}$

2.1.5 $2^{\prime}, 7^{\prime}$-Dichlorofluorescein. $\quad 2^{\prime}, 7^{\prime}$-Dichlorofluorescein (DCF, 98.4\%) was purchased from TCI (product D0371, lot 3ABPG, $\left.M_{\mathrm{r}}=401.20\right)$. The molar absorption of DCF at $\lambda=$ $503 \mathrm{~nm}$ dissolved in $10 \mathrm{mM}$ phosphate solution $(\mathrm{pH}=7.2)$ was determined: $\varepsilon_{503}$ (DCF) $=101900 \mathrm{M}^{-1} \mathrm{~cm}^{-1}$ (Fig. S-3, ESI $\dagger$ ). This value is in good agreement with the spectrum given by (Chignell and Sik, 2003), ${ }^{43}$ but disagrees with the value given by (Ischiropoulos et al., 1999), ${ }^{41}$ see the known pH-dependency of $\varepsilon_{503}(\text { DCF })^{38}$ and Fig. S-3, ESI. $\dagger$

2.1.6. Glass fiber filters and other chemicals. Whatman binder-free borosilicate glass fiber filters were from GE Healthcare (grade GF/D, diameter $7 \mathrm{~mm}$, cat. number 1823-007, lot 12887121), see (Yoshimoto et al., 2018). ${ }^{52}$ Dimethylsulfoxide (DMSO, >99.7\%) was from Acros Organics.

\subsection{UV/vis spectrophotometers}

Molar absorption coefficient determinations and kinetic measurements in bulk solution were carried out with a JASCO V670 or a SPECORD S600 spectrophotometer (from Analytik Jena) using quartz cells with path length of either $1.0 \mathrm{~cm}$ or $0.1 \mathrm{~cm}$. For the determination of the concentrations of concentrated 
enzyme or dendronised polymer stock solutions a NanoDrop One instrument was used (from ThermoFisher Scientific). For spectrophotometric quantifications in the flow-through experiments, a Cary 60 spectrophotometer (from Agilent Technologies) was used in addition to the SPECORD S600, using the same cells mentioned above.

\subsection{Enzymatic reactions in bulk aqueous solution}

2.3.1. Stock solutions. For the reactions in bulk solution (PB), the following stock solutions were prepared: $5.0 \mathrm{mM}$ DCFH $_{2}$-DA in DMSO; $2.0 \mathrm{mM}$ DCF-DA in DMSO; $1.0 \mathrm{mM}$ DCF in DMSO; $2 \mathrm{M} \mathrm{H}_{2} \mathrm{O}_{2}$ in $\mathrm{H}_{2} \mathrm{O}$ (daily diluted to 0.9 or $18 \mathrm{mM} \mathrm{H}_{2} \mathrm{O}_{2}$ with $\mathrm{PB}$ ); and $100 \mu \mathrm{M}$ BCA in $\mathrm{PB}$ (the precise concentration being determined through measurement of $A_{280}$ ), $50 \mu \mathrm{M}$ HRP in PB (determined by measuring $A_{403}$ ). All stock solutions were prepared in $1.5 \mathrm{~mL}$ polypropylene tubes and then stored at $T=$ $4{ }^{\circ} \mathrm{C}$.

2.3.2. BCA-catalysed hydrolysis of $\boldsymbol{p}$-NA. For the reactions carried out with $p$-NA as substrate at $\mathrm{pH}=7.2$ and an initial concentration of $1 \mathrm{mM}$, see (Yoshimoto et al., 2018); $;^{52}$ the molar absorption coefficient used for $p$-nitrophenolate was $\varepsilon_{405}(p$ nitrophenolate) $=10510 \mathrm{M}^{-1} \mathrm{~cm}^{-1} \cdot{ }^{61}$

2.3.3. $\mathrm{HRP} / \mathrm{H}_{2} \mathrm{O}_{2}$-catalysed oxidation of $\mathrm{ABTS}^{2-}$. The formation of ABTS $^{--}$from ABTS $^{2-}$ with $\mathrm{HRP}$ and $\mathrm{H}_{2} \mathrm{O}_{2}$ as oxidant was determined spectrophotometrically by using $\varepsilon_{414}$ $\left(\mathrm{ABTS}^{\circ-}\right)=36000 \mathrm{M}^{-1} \mathrm{~cm}^{-1},{ }^{23}$ see (Hou et al., 2019). ${ }^{59}$

2.3.4. Reactions of $\mathrm{DCFH}_{2}$-DA in the presence of different amounts of BCA, HRP and $\mathrm{H}_{2} \mathrm{O}_{2}$. Various reaction mixtures containing DCFH $_{2}$-DA ( $50 \mu \mathrm{M}$ in PB, 1 vol\% DMSO, $\left.1 \mathrm{~mL}\right)$ and different amounts of BCA, HRP, and $\mathrm{H}_{2} \mathrm{O}_{2}$ were prepared from the different stock solutions and then analysed spectrophotometrically during $15 \mathrm{~h}$ at $25^{\circ} \mathrm{C}$. As an example, the procedure for preparing a reaction mixture that initially contained $50 \mu \mathrm{M}$ DCFH $_{2}$-DA, $1.0 \mu \mathrm{M}$ BCA, 0.5 $\mu \mathrm{M} \mathrm{HRP}$, and $9.0 \mu \mathrm{M} \mathrm{H}_{2} \mathrm{O}_{2}$, is described in the following. To $960 \mu \mathrm{L} \mathrm{PB}$ placed inside a $1.0 \mathrm{~cm} /$ $1.4 \mathrm{~mL}$ quartz cuvette, $10 \mu \mathrm{L}$ HRP stock solution (50 $\mu \mathrm{M}$ in PB), $10 \mu \mathrm{L}$ BCA stock solution $(100 \mu \mathrm{M}$ in $\mathrm{PB})$ and $10 \mu \mathrm{L} \mathrm{H}_{2} \mathrm{O}_{2}$ stock solution (0.9 mM in $\mathrm{PB})$ were added and mixed gently. After the addition of $10 \mu \mathrm{L} \mathbf{D C F H}_{2}$-DA stock solution ( $5 \mathrm{mM}$ in DMSO), the cuvette was closed with a stopper, and after gentle mixing the UV/vis spectrum was recorded between 240 and $600 \mathrm{~nm}$ at $25{ }^{\circ} \mathrm{C}$ in 5 min intervals for $900 \mathrm{~min}$.

For variations of the concentrations of BCA $(0$ or $0.5-3.0 \mu \mathrm{M}$ in the cuvette), $\mathrm{HRP}$ ( 0 or $0.25-1.50 \mu \mathrm{M}$ in the cuvette) and $\mathrm{H}_{2} \mathrm{O}_{2}$ ( 0 or $4.5-27 \mu \mathrm{M}$ in the cuvette), the same type of stock solutions were used, but the volumes added were adjusted accordingly, balancing the total volume $(1 \mathrm{~mL})$ with $\mathrm{PB}$. For low concentrations of HRP (2.5-7.5 nM in the cuvette), the HRP stock solution (50 $\mu \mathrm{M}$ in $\mathrm{PB}$ ) was first diluted 100 -fold before use. For reactions with an initial hydrogen peroxide concentration of $\left[\mathrm{H}_{2} \mathrm{O}_{2}\right]_{0}=$ $180 \mu \mathrm{M}$, a $18 \mathrm{mM} \mathrm{H}_{2} \mathrm{O}_{2}$ stock solution (in $\mathrm{PB}$ ) was used.

2.3.5. BCA-catalysed hydrolysis of DCF-DA. To $980 \mu \mathrm{L} \mathrm{PB}$ placed inside a $1.0 \mathrm{~cm} / 1.4 \mathrm{~mL}$ quartz cuvette, $10 \mu \mathrm{L}$ BCA stock solution (100 $\mu \mathrm{M}$ in PB) was added and mixed gently. After addition of $10 \mu \mathrm{L}$ DCF-DA stock solution ( $2 \mathrm{mM}$ in DMSO), the cuvette was closed with a stopper, and after gentle mixing the
$\mathrm{UV} /$ vis spectrum was recorded between 240 and $600 \mathrm{~nm}$ at $25^{\circ} \mathrm{C}$ in $5 \mathrm{~min}$ intervals for $900 \mathrm{~min}$. The final concentrations were 20 $\mu \mathrm{M}$ DCF-DA and $1 \mu \mathrm{M}$ BCA in PB, 1 vol\% DMSO. As the DCF-DA solution was slightly turbid (evident from the light scattering contribution in the absorption spectrum) and became completely transparent during the hydrolysis reaction, only qualitative conclusions were drawn from the measurements during the initial phase of the reaction (i.e., until all DCF-DA was converted and the baseline around $600 \mathrm{~nm}$ became stable).

2.3.6. Stability of DCF towards light, $\mathrm{H}_{2} \mathrm{O}_{2}$ and/or HRP. The stability of DCF in PB was analysed for three different conditions. (1) To $980 \mu \mathrm{L}$ PB placed inside a $1.0 \mathrm{~cm} / 1.4 \mathrm{~mL}$ quartz cuvette, $10 \mu \mathrm{L} \mathrm{H}_{2} \mathrm{O}_{2}$ stock solution ( $0.9 \mathrm{mM}$ in $\left.\mathrm{PB}\right)$ was added and mixed gently. After the addition of $10 \mu \mathrm{L}$ DCF stock solution ( $1 \mathrm{mM}$ in DMSO), the cuvette was closed with a stopper, and after gentle mixing the UV/vis spectrum was recorded between 240 and $600 \mathrm{~nm}$ at $25{ }^{\circ} \mathrm{C}$ in $5 \mathrm{~min}$ intervals for $900 \mathrm{~min}$. After three days, the absorption spectrum of the solution was measured again. (2) In a similar experiment, PB was added instead of the $\mathrm{H}_{2} \mathrm{O}_{2}$ stock solution and the solution was stored outside the spectrophotometer in the dark. (3) In an additional control experiment, the $\mathrm{H}_{2} \mathrm{O}_{2}$ stock solution was replaced by 10 $\mu \mathrm{L}$ of a HRP stock solution (50 $\mu \mathrm{M}$ in $\mathrm{PB})$. In all these control experiments (without $\mathrm{HRP}$ and $\mathrm{H}_{2} \mathrm{O}_{2}$ being present at the same time), the spectra of DCF remained stable.

In order to oxidise DCF (10 $\mu \mathrm{M}$ in PB, 1 vol\% DMSO, $1 \mathrm{~mL})$ catalysed by HRP $(0.5 \mu \mathrm{M})$ with an excess of $\mathrm{H}_{2} \mathrm{O}_{2}(180 \mu \mathrm{M})$ added at once at the beginning, $970 \mu \mathrm{L}$ PB was placed inside a $1.0 \mathrm{~cm} / 1.4 \mathrm{~mL}$ quartz cuvette. $10 \mu \mathrm{L}$ HRP stock solution $(50 \mu \mathrm{M}$ in $\mathrm{PB}$ ) and $10 \mu \mathrm{L} \mathrm{H}_{2} \mathrm{O}_{2}$ stock solution (18 $\mathrm{mM}$ in $\mathrm{PB}$ ) were added and mixed gently. After the addition of $10 \mu \mathrm{L}$ DCF stock solution (1 $\mathrm{mM}$ in DMSO), the cuvette was closed with a stopper, and after gentle mixing the UV/vis spectrum was recorded between 240 and $600 \mathrm{~nm}$ at $25{ }^{\circ} \mathrm{C}$ in 5 min intervals for 3 hours.

In order to oxidise DCF (10 $\mu \mathrm{M}$ in PB, 1 vol\% DMSO, $1 \mathrm{~mL})$ catalysed by $\mathrm{HRP}(0.5 \mu \mathrm{M})$ with an excess of $\mathrm{H}_{2} \mathrm{O}_{2}$ added stepwise, $980 \mu \mathrm{L} \mathrm{PB}$ was placed inside a $1.0 \mathrm{~cm} / 1.4 \mathrm{~mL}$ quartz cuvette. $10 \mu \mathrm{L}$ HRP stock solution ( $50 \mu \mathrm{M}$ in PB) and $10 \mu \mathrm{L}$ DCF stock solution ( $1 \mathrm{mM}$ in DMSO) were added and mixed gently. From now on, the UV/vis spectrum was recorded between 240 and $600 \mathrm{~nm}$ at $25^{\circ} \mathrm{C}$ in $1 \mathrm{~min}$ intervals for 3 hours. After $10 \mathrm{~min}$, $10 \mu \mathrm{L}$ diluted $\mathrm{H}_{2} \mathrm{O}_{2}$ stock solution ( $1 \mathrm{mM}$ in $\mathrm{PB}$ ) was added to the cuvette that was then put back inside the spectrophotometer after gentle mixing. Upon a stable value of $A_{503}$ was reached (several minutes), another $10 \mu \mathrm{L}$ diluted $\mathrm{H}_{2} \mathrm{O}_{2}$ stock solution were added. This process was repeated three more times $(50 \mu \mathrm{L}$ diluted $\mathrm{H}_{2} \mathrm{O}_{2}$ stock solution added, corresponding to 5 equivalents $\mathrm{H}_{2} \mathrm{O}_{2}$ ). Further addition of $5 \mu \mathrm{L}$ diluted $\mathrm{H}_{2} \mathrm{O}_{2}$ stock solution (5.5th equivalent) did not lead to any significant spectral change anymore.

2.3.7. In situ preparation of $\mathrm{DCFH}_{2}$ and subsequent oxidation catalysed by $\mathbf{H R P} / \mathbf{H}_{2} \mathbf{O}_{2}$. $\mathbf{D C F H}_{2}$ was prepared in situ by hydrolysis of $\mathbf{D C F H}_{2}$-DA with excess $\mathrm{NaOH}$. $960 \mu \mathrm{L}$ PB was placed inside a $1.0 \mathrm{~cm} / 1.4 \mathrm{~mL}$ quartz cuvette. $10 \mu \mathrm{L}$ of $\mathrm{NaOH}$ ( $2 \mathrm{M}$ in water) was added and mixed well. In a next step, $10 \mu \mathrm{L}$ of a DCFH $_{2}$-DA stock solution (5 $\mathrm{mM}$ in DMSO) was added to the cuvette and after mixing, the UV/vis spectrum was recorded 
between 240 and $600 \mathrm{~nm}$ at $25{ }^{\circ} \mathrm{C}$ in 5 min intervals. After the spectrum did not change anymore, $20 \mu \mathrm{L}$ of $\mathrm{HCl}(1 \mathrm{M}$ in water) was added to re-adjust the $\mathrm{pH}$ to the initial value of 7.2. To this solution containing DCFH $_{2}(50 \mu \mathrm{M}, 1 \mathrm{~mL}), 10 \mu \mathrm{L}$ HRP stock solution (50 $\mu \mathrm{M}$ in $\mathrm{PB})$ and $10 \mu \mathrm{L}$ diluted $\mathrm{H}_{2} \mathrm{O}_{2}$ stock solution (0.9 $\mathrm{mM}$ in $\mathrm{PB}$ ) were added and after quick mixing, the formation of DCF was quantified.

In another experiment, $\mathbf{D C F H}_{2}(50 \mu \mathrm{M})$ was added stepwise to already present $\mathrm{HRP}(0.5 \mu \mathrm{M})$ and $\mathrm{H}_{2} \mathrm{O}_{2}(9 \mu \mathrm{M})$. First, a 500 $\mu \mathrm{M} \mathrm{DCFH}_{2}$ solution was prepared as described above in a buffer volume of $0.1 \mathrm{~mL}$ instead of $1 \mathrm{~mL}$. From this $500 \mu \mathbf{M} \mathbf{D C F H}_{2}$ solution, $2 \mu \mathrm{L}$ were added to a $1 \mathrm{~mL}$ solution containing HRP $(0.5 \mu \mathrm{M})$ and $\mathrm{H}_{2} \mathrm{O}_{2}(9 \mu \mathrm{M})$ every 30 seconds for 4 minutes, followed by mixing and taking an absorption spectrum every minute. After thereby having added $\sim 10 \mu \mathrm{M}$ of $\mathbf{D C F H} \mathbf{H}_{2}$ over the first $4 \mathrm{~min}$, it was equilibrated for another $4 \mathrm{~min}$ and found to remain stable, indicating full $\mathrm{H}_{2} \mathrm{O}_{2}$ consumption. Addition of the remaining $\sim 40 \mu \mathrm{M}$ of $\mathbf{D C F H}_{2}$ (80 $\mu \mathrm{L}$ of the $500 \mu \mathrm{M}$ stock solution after $15 \mathrm{~min}$ ) did not lead to significant changes in the spectrum above $\lambda=330 \mathrm{~nm}$.

\subsection{Preparation of the denpol-enzyme conjugates de- PG2 ${ }_{1000}-\mathrm{BAH}-\mathrm{BCA}$ and de-PG2 ${ }_{1000}-\mathrm{BAH}-\mathrm{HRP}$}

Two different types of dendronised polymer (denpol)-enzyme conjugates were prepared in this work, abbreviated as dePG2 ${ }_{1000}$-BAH-BCA and de-PG2 ${ }_{1000}-\mathrm{BAH}-\mathrm{HRP}$. BAH stands for bisaryl hydrazone and indicates the type of covalent bond through which the enzyme molecules were bound to de-PG2 $2_{1000}$. Quantification of the average number of $\mathrm{BAH}$ and enzyme molecules bound per 1000 repeating units (r.u.) long dendronised polymer molecules yielded 86 and 90 in the case of HRP (i.e., about one $\mathrm{BAH}$ bond per HRP molecule): de-PG2 $2_{1000}-\mathrm{BAH}_{86}-\mathrm{HRP}_{90}$. In the case of BCA, two conjugates were prepared, abbreviated as de$\mathrm{PG}_{1000}-\mathrm{BAH}_{152}-\mathrm{BCA}_{101}$ and de-PG2 $2_{1000}-\mathrm{BAH}_{207}-\mathrm{BCA}_{152}$. For both $\mathrm{BCA}$ conjugates, on average more than one $\mathrm{BAH}$ bond was estimated to have formed per BCA molecule, the molar BCA/BAH ratio being 0.66 and 0.73 , respectively. ${ }^{52}$ In Fig. 1, the chemical structures of an unmodified r.u. of de-PG $2_{1000}$ and of a r.u. to which one enzyme molecule is bound via a BAH bond are shown, together with a simple visualisation of how the enzyme molecules might be packed along the denpol chain for the average enzyme loadings determined experimentally.

For the BCA-conjugates, details about their synthesis, purification and quantification are given in (Yoshimoto et al., 2018); ${ }^{22}$ for the HRP-conjugate, see (Hou et al., 2019). ${ }^{59}$ Additional information is provided in the ESI (Section 4) with Fig. S-4 and S-5. $\dagger$ If stored in aqueous solution at $4{ }^{\circ} \mathrm{C}$, both types of conjugates are stable over prolonged periods of time. ${ }^{52,59}$

\subsection{Immobilisation of de-PG $2_{1000}{ }^{-B A H-B C A}$ and de-PG $2_{1000^{-}}$ BAH-HRP in glass fiber filters}

The prepared denpol-enzyme conjugates were immobilised in glass fiber filters in a similar way as described previously, see (Yoshimoto et al., 2018). ${ }^{52}$ Before use, the glass fiber filters were first washed by immersing them 3 times for 10 min in $5 \mathrm{~mL}$ fresh ethanol. The filters were let dry under ambient conditions

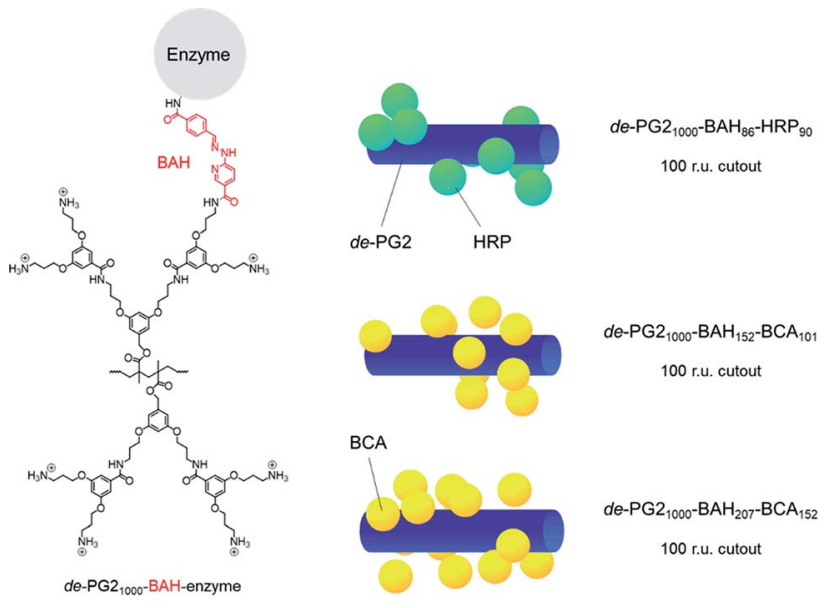

Fig. 1 Left: Chemical structure of one r.u. of the dendronised polymer (denpol) de-PG2 1000 (bottom) in its fully protonated state, and of one r.u. to which an enzyme molecule is bound via a bis-aryl hydrazone (BAH) bond (top); "de-PG2 1000 " stands for "deprotected dendronized polymer of second generation consisting of 1000 r.u. on average and a polymethacrylate backbone". The different denpol-enzyme conjugates prepared had various average numbers of $\mathrm{BAH}$ bonds and enzyme molecules per average denpol chain. Right: Simplified visualisation of a possible packing of the enzymes molecules along a 100 r.u. long denpol chain (represented as blue cylinder): de-PG2 $1000^{-}$ $\mathrm{BAH}_{86}-\mathrm{HRP}_{90}$, de-PG2 ${ }_{1000}-\mathrm{BAH}_{152}-\mathrm{BCA}_{101}$, and de-PG2 $1000-\mathrm{BAH}_{207^{-}}$ $B C A_{152}$. The enzyme molecules are represented as green (HRP) or yellow (BCA) spheres. The schematic representations show that the experimentally determined average number of enzymes molecules per average denpol chain are spatially feasible. Higher enzyme loadings along the denpol chains seem spatially possible, see ESI† for details about the visualisation.

until no change in weight could be observed anymore ( $\mathrm{ca} .30$ min). In the following, the general procedure for the immobilisation of the denpol-enzyme conjugates in the filters via simple adsorption from aqueous solution is described; for some of the experiments, this general procedure was modified. Although no major changes resulted from those modifications, they are summarised in the ESI (Section 5). $\dagger$

2.5.1. Immobilisation of either denpol-BCA or denpolHRP. To each filter, $50 \mu \mathrm{L}$ of an aqueous buffer solution containing one of the conjugates were added, either a solution containing de-PG2 $2_{1000}-\mathrm{BAH}_{207}-\mathrm{BCA}_{152}$, or a solution containing de-PG2 ${ }_{1000}-\mathrm{BAH}_{86}-\mathrm{HRP}_{90}$. The added volume $(50 \mu \mathrm{L})$ was taken up by the filter through capillary forces. The denpol-BCA conjugate solution used was prepared from a stock solution obtained from the conjugate preparation according to an optimised protocol using a $100 \mathrm{mM}$ sodium phosphate buffer solution ( $\mathrm{pH}=7.2,1.15 \mathrm{M} \mathrm{NaCl}$ ), see (Yoshimoto et al., 2018). ${ }^{52}$ This stock solution was desalted by repetitive ultrafiltration with an Amicon-0.5 mL (10 kDa MWCO) ultrafiltration device using $\mathrm{PB}$, resulting in $[\mathrm{BAH}]=12 \mu \mathrm{M}$ (determined by measuring $A_{354}$ and taking into account $\varepsilon_{354}(\mathrm{BAH})=29000 \mathrm{M}^{-1} \mathrm{~cm}^{-1}$ ), see (Yoshimoto et al., 2018). ${ }^{52}$ The corresponding concentration of BCA in this desalted denpol-BCA conjugate solution was [BCA] $=8.8 \mu \mathrm{M}$. The denpol-HRP conjugate solution used was prepared from a stock solution obtained from the conjugate preparation according to a previously published protocol using 
a $10 \mathrm{mM}$ sodium phosphate buffer solution $(\mathrm{pH}=7.0,0.15 \mathrm{M}$ $\mathrm{NaCl}$ ), see (Hou et al., 2019). ${ }^{59}$ This stock solution was diluted with the same buffer solution to $[\mathrm{HRP}]=0.5 \mu \mathrm{M}$, determined by activity measurements using $\mathrm{ABTS}^{2-}$ and $\mathrm{H}_{2} \mathrm{O}_{2}$ as substrates and a calibration curve for free HRP, see (Hou et al. 2019) for details. ${ }^{59}$ For control measurements with "empty" filters, pure $\mathrm{PB}$ or pure $10 \mathrm{mM}$ sodium phosphate buffer solution $(\mathrm{pH}=7.0$, $0.15 \mathrm{M} \mathrm{NaCl}$ ) was used.

The wetted filters were put inside closed $2 \mathrm{~mL}$ polypropylene tubes and stored for $1 \mathrm{~h}$ at room temperature. The filters were then placed in a home-made filter holder ${ }^{52}$ and washed for $3 \mathrm{~h}$ by using a peristaltic pump (P-1 from Pharmacia) at 200 $\mu \mathrm{L} \min ^{-1}$ with either PB (in the case of the denpol-BCA conjugate and for control filters treated with $\mathrm{PB}$ only), or with a $10 \mathrm{mM}$ sodium phosphate buffer solution, $\mathrm{pH}=7.0$, containing $0.15 \mathrm{M} \mathrm{NaCl}$ (in the case of the denpol-HRP conjugates and the corresponding control filters). If not immediately used (or after buffer washing following activity measurements, see below) the washed, buffer immersed filters were stored inside a refrigerator at $4{ }^{\circ} \mathrm{C}$ with both ends of the filter holder closed with parafilm.

2.5.2. Co-immobilisation of denpol-BCA and denpol-HRP. For the experiments in which both enzymes were immobilised in one and the same filter, $50 \mu \mathrm{L}$ of an aqueous solution containing denpol-BCA as well as denpol-HRP were added to the filter followed by incubation for $1 \mathrm{~h}$ at room temperature, as described above. This solution was prepared by mixing diluted solutions of de-PG2 $2_{1000}-\mathrm{BAH}_{207}-\mathrm{BCA}_{152}$ (in $\mathrm{PB}, 80 \mathrm{vol} \%$ ) and de$\mathrm{PG} 2_{1000}-\mathrm{BAH}_{86}-\mathrm{HRP}_{90}$ (in $10 \mathrm{mM}$ phosphate, $\mathrm{pH}=7.0,0.15 \mathrm{M}$ $\mathrm{NaCl}, 20 \mathrm{vol} \%$ ). Thereby, the enzyme concentrations in this mixture were $4.4 \mu \mathrm{M}$ BCA and $0.25 \mu \mathrm{M}$ HRP and the buffer system was the same as for sequential immobilisation (see below). After loading two glass fiber filters with $50 \mu \mathrm{L}$ (each) of this mixture, the same total amounts of enzyme molecules were added to the two filters as in the case of the single filter loadings with one denpol-enzyme conjugate only (440 pmol BCA and 25 pmol HRP). Both filters were then placed stacked in the homemade filter holder ${ }^{52}$ and washed, as described above, with the exception that always PB was used for washing.

2.5.3. Sequential immobilisation of denpol-BCA and denpol-HRP. For the experiments in which both enzymes were immobilised in two different filters but stacked in the same filter holder, $50 \mu \mathrm{L}$ of an aqueous solution containing either denpol-BCA or denpol-HRP were added separately in two filters followed by incubation for $1 \mathrm{~h}$ at room temperature, using concentrations as described above for placing only one type of denpol-enzyme in the filter holder (2.5.1). This time though, the two individual incubation solutions (containing only one type of denpol-enzyme each) were prepared/diluted such that each filter was incubated under the same buffer conditions as for the co-immobilisation $(80 \% \mathrm{~PB}, 20 \%$ of $10 \mathrm{mM}$ phosphate, $\mathrm{pH}=$ 7.0, $0.15 \mathrm{M} \mathrm{NaCl}$ ), in order to compare the two immobilisation methods under conditions as equal as possible. Consequently, the two filters (containing one type of denpol-enzyme each) were stacked in the same filter holder (BCA before HRP in flow direction) before washing with $\mathrm{PB}$, as described above.

\subsection{Measurements of the activity of immobilised denpol- BCA and denpol-HRP}

2.6.1. BCA activity measurements using $p$-NA as substrate. From a $100 \mathrm{mM} p$-NA stock solution (prepared in acetonitrile, $\left.\mathrm{CH}_{3} \mathrm{CN}\right)$, a $1 \mathrm{mM}$-NA solution in $\mathrm{PB}$ was freshly prepared $(\mathrm{pH}$ $\left.=7.2,1 \mathrm{vol} \% \mathrm{CH}_{3} \mathrm{CN}\right)$. This substrate solution was passed

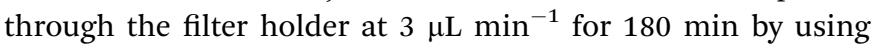
a syringe pump (AL1000 from World Precision Instruments). Every $3 \mathrm{~min}, 2 \mu \mathrm{L}$ were sampled from the outflow with a Gilson Pipetman P10, and the absorption spectrum was measured with the NanoDrop One instrument $(l=0.1 \mathrm{~cm}$, background: $\mathrm{PB})$. Values of $A_{405}$ were taken as a measure of the formed $p$-nitrophenolate. The total concentration of $p$-nitrophenolate $+p$ nitrophenol in the outflow was calculated on the basis of $\varepsilon_{405}$ ( $p$ nitrophenolate) $=10510 \mathrm{M}^{-1} \mathrm{~cm}^{-1},{ }^{61}$ and [ $p$-nitrophenolate]/ $[p$-nitrophenol $]=1.15$ at $\mathrm{pH} 7.2$ using $\mathrm{p} K_{\mathrm{a}}(p$-nitrophenol $)=$ 7.14. ${ }^{52}$ Since $p$-NA undergoes significant autohydrolysis, reference measurements were carried out with "empty" filters (PB only). Data for this non-enzymatic $p$-NA hydrolysis were subtracted from the data obtained for the filter with immobilised BCA.

2.6.2. HRP activity measurements with $\mathrm{ABTS}^{2-}$ and $\mathrm{H}_{2} \mathrm{O}_{2}$ as substrates. A substrate solution of $\left[\mathrm{ABTS}^{2-}\right]=1 \mathrm{mM}$ and $\left[\mathrm{H}_{2} \mathrm{O}_{2}\right]=0.2 \mathrm{mM}$ was freshly prepared in $10 \mathrm{mM}$ sodium phosphate buffer solution $(\mathrm{pH}=7.0,0.15 \mathrm{M} \mathrm{NaCl})$. This substrate solution was pumped through the filter holder at 200 $\mu \mathrm{L} \min ^{-1}$ for 84 min by using a peristaltic pump (P-1 from Pharmacia). The filter holder was connected to a quartz glass flow-through cell (176-765-QS from Hellma Analytics, $l=1.0$ $\mathrm{cm})$. Absorption spectra were recorded every $3 \mathrm{~min}$ with a Cary 60 spectrophotometer (background: same buffer as substrate solution). Values of $A_{414}$ were taken as a measure of formed $\operatorname{ABTS}^{\cdot-}\left(\varepsilon_{414}\left(\mathrm{ABTS}^{\circ-}\right)=36000 \mathrm{M}^{-1} \mathrm{~cm}^{-1}\right) .^{23}$

2.6.3. Participation of $\mathrm{BCA}$ and $\mathrm{HRP}$ in the cascade reaction occurring with DCFH $\mathrm{H}_{2}$-DA and $\mathrm{H}_{2} \mathrm{O}_{2}$ as substrates. From a stock solution of $\mathbf{D C F H}_{2}$-DA ( $5 \mathrm{mM}$ in DMSO) and a diluted stock solution of $\mathrm{H}_{2} \mathrm{O}_{2}\left(0.9 \mathrm{mM}\right.$ in $\mathrm{PB}$, prepared from a $2 \mathrm{M} \mathrm{H}_{2} \mathrm{O}_{2}$ stock solution in water) a solution containing $50 \mu \mathbf{M} \mathbf{D C F H}_{2}$-DA and $9 \mu \mathrm{M} \mathrm{H}_{2} \mathrm{O}_{2}$ was freshly prepared in $\mathrm{PB}(\mathrm{pH}=7.2,1 \mathrm{vol} \%$ DMSO). This substrate solution was passed through the filter holder at $5 \mu \mathrm{L} \min ^{-1}$ for 180 min by using a syringe pump (AL1000 from World Precision Instruments). The outflow was collected in $1.5 \mathrm{~mL}$ polypropylene tubes, using a new, empty tube every $30 \mathrm{~min}$. The absorption spectra of the collected outflows were measured with a spectrophotometer (quartz glass cell, $l=1 \mathrm{~cm}$, background: $\mathrm{PB})$. The performance of the immobilised enzymes was evaluated by plotting $A_{503}$ as a function of time, yielding approximate values for the concentration of DCF, using $\varepsilon_{503}$ (DCF) $=101900 \mathrm{M}^{-1} \mathrm{~cm}^{-1}$ (see Fig. S-3, ESI $\dagger$ ). For the collected final outflow ( $t=150-180 \mathrm{~min})$, the full absorption spectrum was analysed with the analytical methods already applied for the cascade reactions in bulk solution, as described in "Results and discussion" (Section 3.1.6.). 

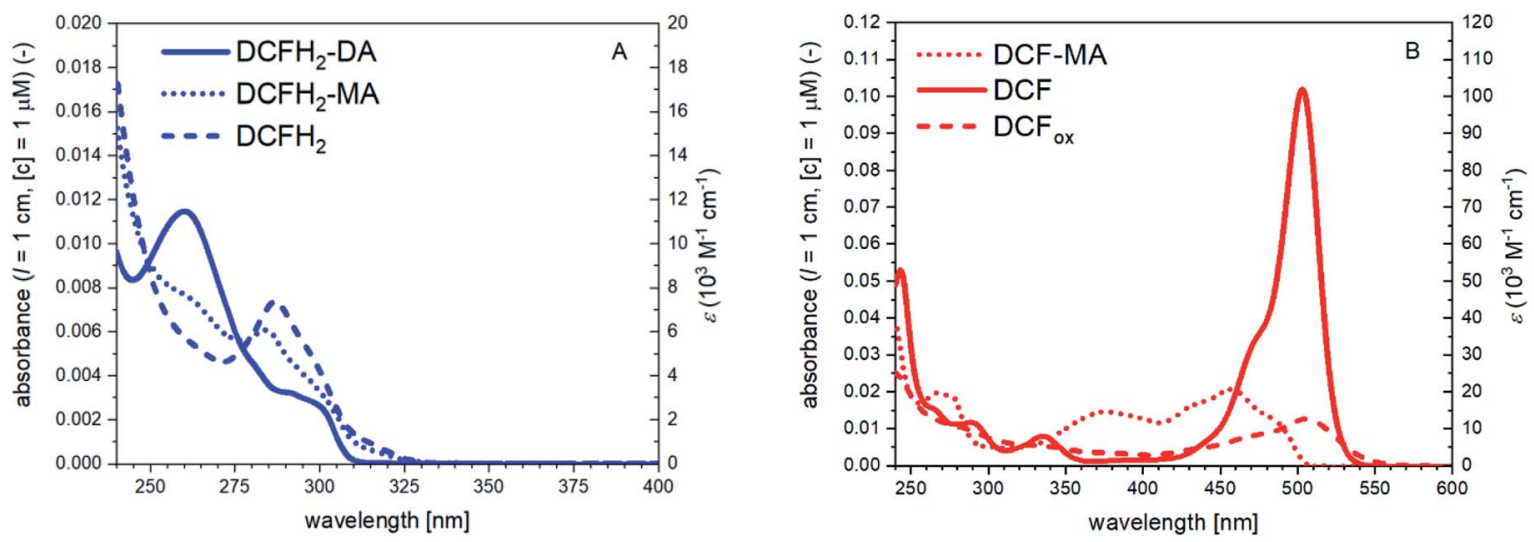

Fig. $2 U$ U/vis absorption spectra between $\lambda=240$ and $600 \mathrm{~nm}$ of all substrates, intermediates and products of the cascade reaction. (A) Reduced compounds $\mathrm{DCFH}_{2}-\mathrm{DA}, \mathrm{DCFH} \mathrm{H}_{2}-\mathrm{MA}$, and DCFH $\mathrm{C}_{2}$ (as obtained from complete $\mathrm{DCFH}_{2}-\mathrm{DA}$ hydrolysis using $\mathrm{NaOH}$ ). (B) Oxidised compounds DCFMA, DCF, and DCF ox (as obtained from DCF with more than 5 equivalents $\mathrm{H}_{2} \mathrm{O}_{2}$ in the presence of $\mathrm{HRP}$, see Fig. S- $8, \mathrm{ESI}+$ ). $\mathrm{H}_{2} \mathrm{O}_{2}$ did not have a significant absorption under the conditions used. On the left vertical axes, the absorbance normalised to $1 \mu \mathrm{M}$ solutions (PB, $\mathrm{pH}=7.2)$ are given, either as measured with quartz cells using solutions with about ten times higher concentrations, or as obtained by fitting (dotted lines), or as obtained by in situ preparation (dashed lines). The molar absorption coefficients are indicated on the right vertical axes (see also Table S-1, ESI $†$ ). See text for details.

\section{Results and discussion}

\subsection{Cascade reaction of $\mathrm{DCFH}_{2}$-DA and $\mathrm{H}_{2} \mathrm{O}_{2}$ in bulk} aqueous solution with co-added free BCA and HRP

As summarised in Schemes 1 and 2, the investigated cascade reaction is characterised by two possible reaction pathways (see Introduction). We analysed the reaction in bulk solution in great detail after both enzymes were added from the beginning to a solution containing both substrates DCFH $\mathbf{H}_{2}$-DA and $\mathrm{H}_{2} \mathrm{O}_{2}$, allowing the reaction to proceed not only along pathway 1 but also along pathway 2. If BCA would have been added before HRP to allow for complete hydrolysis of $\mathbf{D C F H}_{2}-\mathbf{D A}$, progress along pathway 2 would have been prevented (not targeted here). For all reactions a $0.01 \mathrm{M}$ sodium phosphate buffer solution was used with $\mathrm{pH}=7.2(\mathrm{~PB})$ at $T=25{ }^{\circ} \mathrm{C}$ with a fixed initial concentration of $\mathbf{D C F H}_{2}$-DA $\left(\left[\mathbf{D C F H}_{2}-\mathbf{D A}\right]_{0}\right)$ of $50 \mu \mathrm{M}$. The concentrations of BCA, HRP and $\mathrm{H}_{2} \mathrm{O}_{2}$ were varied, and the progress of the reactions was followed spectrophotometrically by recording the time-dependent changes in the absorption spectra of the reaction mixtures between $\lambda=240$ and $600 \mathrm{~nm}$.

In the following, we first report on results obtained from a number of control measurements that helped understanding the progress and final outcome of the cascade reaction in dependence of initial $\mathrm{H}_{2} \mathrm{O}_{2}$ concentration and concentrations of BCA and HRP. Thanks to these control measurements, it was possible to finally know the absorption spectra between 240 and $600 \mathrm{~nm}$ of all components of the reaction mixtures (Fig. 2, Table S-1, and Fig. S-6, ESI $\dagger$ ). This allowed for a molecular interpretation of the time-dependent spectral changes occurring in the case of the cascade reaction. In addition, the control measurements made a comparison of the kinetic efficiency for the BCAcatalysed hydrolysis of $\mathbf{D C F H}_{2}$-DA, $\mathbf{D C F H}_{2}$-MA and DCF-MA possible, which greatly helped interpreting the results from the cascade reaction.
3.1.1. Oxidation of DCF catalysed by $\mathrm{HRP}$ and $\mathrm{H}_{2} \mathrm{O}_{2}$. Independent from the reaction pathway, DCF is the product which is obtained from $\mathbf{D C F H}_{\mathbf{2}}$-DA upon two carboxylic acid ester hydrolysis steps and a two-electron oxidation (Scheme 2). The absorption maximum of DCF at $\mathrm{pH}=7.2$ is at $\lambda_{\max }=$ $503 \mathrm{~nm}$ (Fig. S-3, ESI†). From the work of Rota et al. (1999) ${ }^{39}$ it is known that oxidation of DCF can occur in aqueous solution if HRP and $\mathrm{H}_{2} \mathrm{O}_{2}$ are present simultaneously, resulting in the formation of $\mathbf{D C F}^{*}$ or even further oxidation products whose chemical structures are not known (altogether abbreviated as $\mathbf{D C F}_{\mathbf{o x}}$, Scheme 1).

For the conditions we used for the cascade reaction $(T=$ $25{ }^{\circ} \mathrm{C}, \mathrm{pH}=7.2$, see later Section 3.1.6.), we re-investigated the stability of DCF $(10 \mu \mathrm{M})$ in the presence and absence of HRP and $\mathrm{H}_{2} \mathrm{O}_{2}$ by placing different DCF-containing solutions, prepared in quartz cells, inside a spectrophotometer and then recording at a predetermined time interval the absorption spectrum between $\lambda=240$ and $600 \mathrm{~nm}$. The results were the following. Without HRP and $\mathrm{H}_{2} \mathrm{O}_{2}$, dissolved DCF is stable at $\mathrm{pH}=7.2$ for at least 3 days, independent whether the solution is stored (i) within the cell compartment of the spectrophotometer with continuous recording of the spectrum every $5 \mathrm{~min}$ for $18 \mathrm{~h}$ (Fig. S-7A, ESI $\dagger$ ), (ii) in the dark, or (iii) exposed to room light in the laboratory (data not shown). Also the presence of either $\mathrm{H}_{2} \mathrm{O}_{2}(9 \mu \mathrm{M}$, Fig. S-7A, ESI $\dagger)$ or HRP $(0.5 \mu \mathrm{M}$, Fig. S-7B, ESI $\dagger)$ separately did not lead to a significant change in the absorption spectrum of DCF. The situation was very different when both, $\mathrm{H}_{2} \mathrm{O}_{2}$ and $\mathrm{HRP}$, were present, as demonstrated with two types of experiments. In the first one, $\mathrm{H}_{2} \mathrm{O}_{2}$ was added at $\left[\mathrm{H}_{2} \mathrm{O}_{2}\right]_{0}=180$ $\mu \mathrm{M}$ to $10 \mu \mathrm{M}$ DCF and $0.5 \mu \mathrm{M}$ HRP, followed by recording the absorption spectrum every $5 \mathrm{~min}$ up to $3 \mathrm{~h}$ (Fig. S-8A, ESI $\dagger$ ). In the second one, $\mathrm{H}_{2} \mathrm{O}_{2}$ was added in steps of $10 \mu \mathrm{M}$ to $10 \mu \mathrm{M}$ DCF and $0.5 \mu \mathrm{M}$ HRP as long as significant changes in the absorption spectrum were observed (Fig. S-8B, ESI $\dagger$ ). Both types of experiments showed that in the presence of HRP $(0.5 \mu \mathrm{M})$ and 
excess $\mathrm{H}_{2} \mathrm{O}_{2}$, the DCF absorption with $\lambda_{\max }=503 \mathrm{~nm}$ decreased monotonically until $A_{503}$ leveled off at about $1 / 8$ of the initial value. This final value was reached after addition of about $50 \mu \mathrm{M}$ $\mathrm{H}_{2} \mathrm{O}_{2}$ (Fig. S-8C and D, ESI $\dagger$ ), corresponding to 5 equivalents with respect to the concentration of DCF used in the experiments $(10 \mu \mathrm{M})$. It is possible that a lot of the excess $\mathrm{H}_{2} \mathrm{O}_{2}$ during this stepwise addition was decomposed to $\mathrm{O}_{2}$ and $\mathrm{H}_{2} \mathrm{O}$ by the "catalase-like" activity of the high amounts of HRP present, socalled "catalatic" activity. ${ }^{62,63}$ As adding 5.5 and more $\mathrm{H}_{2} \mathrm{O}_{2}$ equivalents did not lead to a further decrease in $A_{503}$, and since there was no change in the spectrum obtained (no band shift or appearance of new bands), the absorption spectrum obtained after addition of 5 equivalents $\mathrm{H}_{2} \mathrm{O}_{2}$ to DCF is considered as the spectrum of oxidised DCF products $\left(\mathbf{D C F}_{\mathbf{o x}}\right)$. Although we are not aware of any detailed investigation of the oxidation of DCF with $\mathrm{HRP} / \mathrm{H}_{2} \mathrm{O}_{2}$, the spectrum of $\mathbf{D C} \mathbf{F}_{\mathbf{o x}}$ we obtained (Fig. 2B) resembles the spectrum reported by (Rota et al., 1999). ${ }^{39}$ Most notably, the remaining absorption bands around $503 \mathrm{~nm}$ are much broader than the ones for DCF, with additional absorption between $\lambda=525$ and $550 \mathrm{~nm}$, a region in which the absorption of DCF is very low or almost zero. This high wavelength absorption seems to be characteristic for $\mathbf{D C F}_{\mathbf{o x}} \cdot{ }^{39}$ The catalatic activity of HRP was tested under similar conditions (0.5 $\mu \mathrm{M}$ HRP, $9 \mu \mathrm{M} \mathrm{H}_{2} \mathrm{O}_{2}$, PB buffer), yielding significant $\mathrm{H}_{2} \mathrm{O}_{2}$ decomposition within a few minutes, i.e., within a similar time frame as in the case of the stepwise addition of $\mathrm{H}_{2} \mathrm{O}_{2}$ to DCF described above (see Fig. S-9, ESI $\dagger$ ). Although the excess $\mathrm{H}_{2} \mathrm{O}_{2}$ consumption needed to oxidise DCF to $\mathbf{D C F}_{\mathbf{o x}}$ might possibly have several additional reasons $\left(\mathrm{H}_{2} \mathrm{O}_{2}\right.$ destabilisation by DCF, reduction of $\left.\mathbf{D C F}^{*}\right),{ }^{39,51}$ it became clear that under the experimental conditions we used, HRP-catalysed DCF oxidation always was in competition with HRP-catalysed $\mathrm{H}_{2} \mathrm{O}_{2}$ oxidation (catalatic activity of HRP).

3.1.2. Hydrolysis of DCFH $_{2}$-DA catalysed by BCA. The stability of $\mathbf{D C F H}_{2}$-DA was investigated in $\mathrm{PB}(\mathrm{pH}=7.2)$ at $T=$ $25{ }^{\circ} \mathrm{C}$ for different conditions in the presence or absence of BCA. Seven control experiments were carried out, always with $\left[\mathbf{D C F H}_{\mathbf{2}}-\mathbf{D A}\right]_{0}=50 \mu \mathrm{M}$. Changes in the absorption spectrum were recorded when none, one or two of the three additional components of the cascade reaction (BCA, HRP, $\mathrm{H}_{2} \mathrm{O}_{2}$ ) were present. This means that in each control measurement at least one component of the cascade reaction was missing. The chosen concentrations of BCA, HRP, and $\mathrm{H}_{2} \mathrm{O}_{2}$ were the standard concentrations used later on for the actual cascade reaction, see Section 3.1.6.

Control 1: $\mathbf{D C F H} \boldsymbol{H}_{2}-\mathbf{D A}$ only. The absorption spectrum of DCFH $_{2}$-DA dissolved in $\mathrm{PB}$ at $\mathrm{pH}=7.2$ is shown in Fig. 2A. The spectrum has an absorption maximum at $\lambda=260 \mathrm{~nm} \cdot{ }^{64}$ As shown in Fig. S-10, ESI, $\dagger$ the spectrum of dissolved DCFH $_{2}$-DA (50 $\mu \mathrm{M}$ in $\mathrm{PB}$ ) did not change much upon storage for up to $15 \mathrm{~h}$ at $T=25{ }^{\circ} \mathrm{C}$. There was only a slight decrease in $A_{260}$ with time and a very small increase in $A_{287}$ (slow auto-hydrolysis). $A_{503}$ remained almost zero.

Controls 2 and 3: $\mathbf{D C F H}-\mathbf{D A}+\mathrm{HRP}$ and $\mathbf{D C F H}-\mathbf{D A}+\mathrm{H}_{2} \mathrm{O}_{2}$. The situation is practically the same as for Control 1 when $\mathbf{D C F H}_{2}$ DA $(50 \mu \mathrm{M})$ was incubated for $15 \mathrm{~h}$ with either $0.5 \mu \mathrm{M}$ HRP (Fig. S-11, ESI $\dagger$ ) or $9 \mu \mathrm{M} \mathrm{H}_{2} \mathrm{O}_{2}$ (Fig. S-12, ESI $\dagger$ ).
Control 4: $\mathbf{D C F H} \boldsymbol{H}_{2}-\mathbf{D A}+B C A$. Incubation of $\mathbf{D C F H}_{2}$-DA $(50 \mu \mathrm{M})$ with either 1.0 $\mu \mathrm{M}$ BCA (Fig. S-13, ESI $\dagger$ ) or $2.0 \mu \mathrm{M}$ BCA (Fig. S-14, ESI $\dagger$ ) resulted in (i) clear changes of $A_{260}$ (decrease) and $A_{287}$ (increase) due to $\mathbf{D C F H}$-DA hydrolysis, as well as (ii) appearance of a band with low intensity at $\lambda_{\max }=503 \mathrm{~nm}$. Although $A_{503}$ remained low, its small increase with time indicates that the formation of DCF can occur from hydrolysed $\mathbf{D C F H}_{\mathbf{2}}$-DA without an oxidative enzyme (Fig. 2B). This observation is in agreement with the results of studies by Rota et al. (1999), ${ }^{39}$ which showed that auto-oxidation of the intermediate $\mathbf{D C F H}_{2}$ to DCFH ${ }^{*}$ and DCF can occur to some extent (Scheme 1).

As an intermediate conclusion of Controls 1-4, the measurements showed that (i) dissolved DCFH $_{2}$-DA $(50 \mu \mathrm{M})$ in $\mathrm{PB}(\mathrm{pH}=7.2)$ is relatively stable during the time of the experiments (negligible non-enzymatic hydrolysis); (ii) the presence of HRP $(0.5 \mu \mathrm{M})$ or $\mathrm{H}_{2} \mathrm{O}_{2}(9 \mu \mathrm{M})$ does not affect the stability of DCFH $_{2}$-DA; (iii) BCA $(1.0$ or $2.0 \mu \mathrm{M})$ catalyses the hydrolysis of DCFH $_{2}$-DA with appearance of a band centered around $\lambda=$ $287 \mathrm{~nm}$ and formation of small amounts of DCF. After $15 \mathrm{~h}$ at $T$ $=25{ }^{\circ} \mathrm{C}$, the concentration of formed DCF was $0.14 \mu \mathrm{M}$ for 1.0 $\mu \mathrm{M}$ BCA and $0.16 \mu \mathrm{M}$ for $2.0 \mu \mathrm{M}$ BCA (Fig. S-13 and S-14, ESI $\dagger$ ).

Control 5: $\boldsymbol{D C F H}_{2}$-DA $+B C A+H R P$. $\mathbf{D C F H}_{2}$-DA $(50 \mu \mathrm{M})$ was incubated with BCA (either 1.0 or $2.0 \mu \mathrm{M}$ ) and $0.5 \mu \mathrm{M}$ HRP (without $\mathrm{H}_{2} \mathrm{O}_{2}$ ), see Fig. S-15, ESI $\dagger$ for $1.0 \mu \mathrm{M}$ BCA and Fig. S-16, $\mathrm{ESI}, \dagger$ for $2.0 \mu \mathrm{M}$ BCA. In both cases, hydrolysis of $\mathbf{D C F H}_{2}$-DA occurred with more pronounced formation of DCF as in the absence of HRP. After $15 \mathrm{~h}$ at $T=25{ }^{\circ} \mathrm{C}$, the concentration of DCF was $0.4 \mu \mathrm{M}$ for $1.0 \mu \mathrm{M}$ BCA and $0.55 \mu \mathrm{M}$ for $2.0 \mu \mathrm{M}$ BCA.

Control 6: $\mathbf{D C F H}-\mathbf{D A}+\mathrm{BCA}+\mathrm{H}_{2} \mathrm{O}_{2}$. DCFH $\mathbf{D H A}_{2}$-DA $(50 \mu \mathrm{M})$ was incubated with $1.0 \mu \mathrm{M}$ BCA and $9 \mu \mathrm{M} \mathrm{H}_{2} \mathrm{O}_{2}$ (without HRP), see Fig. S-17, ESI. $\dagger$ The results were very similar to those for the incubation of $\mathbf{D C F H}_{2}$-DA $(50 \mu \mathrm{M})$ with $1.0 \mu \mathrm{M}$ BCA only (Fig. S13, ESI $\dagger$ ). After $15 \mathrm{~h}$ at $T=25{ }^{\circ} \mathrm{C}$, the concentration of formed DCF was $0.13 \mu \mathrm{M}$ (Fig. S-17, ESI $\dagger$ ).

Control 7: $\mathbf{D C F H}-\mathbf{D A}+\mathrm{HRP}+\mathrm{H}_{2} \mathrm{O}_{2}$. Incubation of $\mathbf{D C F H}-\mathbf{D A}$ $(50 \mu \mathrm{M})$ in the presence of $0.5 \mu \mathrm{M}$ HRP and $9 \mu \mathrm{M} \mathrm{H}_{2} \mathrm{O}_{2}$ (no BCA) represents the situation of non-enzymatic hydrolysis of $\mathbf{D C F H}_{2}$ DA followed by enzymatic oxidation (Fig. S-18, ESI $\dagger$ ). The extent of DCF formation after $15 \mathrm{~h}$ at $T=25{ }^{\circ} \mathrm{C}$ was $0.98 \mu \mathrm{M}$, considerably higher than in the case of Controls 5 and 6 . This confirms the efficiency of $\mathrm{HRP} / \mathrm{H}_{2} \mathrm{O}_{2}$ in oxidising the intermediates DCFH $_{2}$-MA and $\mathbf{D C F H}_{2}$ (Scheme 2).

As a summary of Controls 5-7 it is clear that non-enzymatic oxidation of partially or fully hydrolysed intermediates $\left(\mathbf{D C F H}_{2}\right.$ MA or $\mathbf{D C F H}_{2}$ ) can occur, in agreement with literature. ${ }^{39}$ For efficient oxidations, however, both HRP and $\mathrm{H}_{2} \mathrm{O}_{2}$ must be present, see below.

Quantitative conclusions drawn from the BCA catalysed hydrolysis of $\mathbf{D C F H} \boldsymbol{H}_{2}-\mathbf{D A}$ ("Control 4" above). As mentioned above, the data shown in Fig. S-13 and S-14, ESI, $\dagger$ reflect the BCA-catalysed hydrolysis of $\mathbf{D C F H}_{2}-\mathbf{D A}$, i.e., the time-dependent disappearance of $\mathbf{D C F H}_{2}$-DA, the transient formation of $\mathbf{D C F H}_{2}-\mathbf{M A}$ and the formation of the completely hydrolysed product $\mathbf{D C F H}_{2}$ (with formation of only negligible amounts of DCF). The recorded time-dependent spectral changes for this two-step hydrolysis of $\mathbf{D C F H}_{2}$-DA (Hyd_1 and Hyd_2 in Scheme 2) was 
Table 1 Important isosbestic points $\left(\lambda_{\text {iso }}\right)$ with the corresponding molar absorption coefficients $\left(\varepsilon_{\lambda}\right)$ used for the quantitative analysis of the reaction mixtures

\begin{tabular}{|c|c|c|}
\hline Molecules & $\lambda_{\text {iso }}(\mathrm{nm})$ & $\varepsilon_{\lambda}\left(\mathrm{M}^{-1} \mathrm{~cm}^{-1}\right)$ \\
\hline $\mathrm{DCFH}_{2}$-DA/DCFH ${ }_{2}$-MA & 276 & 5600 \\
\hline DCFH $_{2}$-MA/DCFH ${ }_{2}$ & 279 & 5600 \\
\hline \multirow{3}{*}{ DCF-MA/DCF } & 284 & 11400 \\
\hline & 340 & 7200 \\
\hline & 460 & 19800 \\
\hline
\end{tabular}

analysed by taking into account the known absorption spectra of $\mathbf{D C F H}_{2}$-DA and $\mathbf{D C F H}_{2}$ (Fig. 2A), the latter being obtained through complete hydrolysis of $\mathbf{D C F H}_{\mathbf{2}}$-DA with hydroxide ions (see Materials and methods). The spectral changes show two isosbestic points, the first one appearing at the beginning of the reaction $\left(\lambda_{\text {iso }}=276 \mathrm{~nm}\right.$, Fig. S-13C, ESI $\left.\dagger\right)$, reflecting coexistence of $\mathbf{D C F H}_{2}$-DA and $\mathbf{D C F H}_{2}$-MA (with negligible amounts of $\mathbf{D C F H}_{2}$ ), the second one appearing at the second phase of the reaction $\left(\lambda_{\text {iso }}=279 \mathrm{~nm}\right.$, Fig. $\mathrm{S}-13 \mathrm{~B}$, ESI $\left.\dagger\right)$, reflecting $\mathbf{D C F H}_{2}$-MA and $\mathbf{D C F H}_{2}$ (with negligible amounts of $\mathbf{D C F H}_{\mathbf{2}}-\mathbf{D A}$ ), see Table 1 . Once $A_{279}$ reached a constant value, only $\mathbf{D C F H}_{2}$-MA and $\mathbf{D C F H}_{2}$ were present in the reaction mixture, with a continuous change in their relative amounts until eventually reaction equilibrium was reached. With this, the absorption spectrum of $\mathbf{D C F H}_{2}$-MA could be obtained by manual fitting (Fig. S-13D, ESI $\dagger$ ). The spectrum is shown in Fig. 2A. In Fig. 3, the decrease in $\left[\mathbf{D C F H}_{\mathbf{2}}-\mathbf{D A}\right]$ during the first phase and the decrease in $\left[\mathbf{D C F H}_{2}\right.$-MA $]$ and increase in $\left[\mathbf{D C F H}_{2}\right]$ during the second phase of the reaction are shown for the two reactions with initially $50 \mu \mathbf{M}_{\text {DCFH }}$-DA and either $1.0 \mu \mathrm{M}$ BCA (Fig. 3A) or $2.0 \mu \mathrm{M}$ BCA (Fig. 3B). The beginnings of the second phase were identified as about 300 and $200 \mathrm{~min}$, respectively.

From the exponential decrease of $\left[\mathbf{D C F H}_{\mathbf{2}}-\mathbf{D A}\right]$ and $\left[\mathbf{D C F H}_{2}\right.$ MA] with time, the kinetic efficiency $\left(k_{\text {cat }} / K_{\mathrm{M}}\right)$ was determined by curve fitting under the assumption that $[\mathrm{S}] \ll K_{\mathrm{M}}$ (MichaelisMenten kinetics, $\mathrm{S}$ being $\mathbf{D C F H}_{2}$-DA or $\mathbf{D C F H}_{2}$-MA, $k_{\text {cat }}$ the catalytic constant and $K_{\mathrm{M}}$ the Michaelis constant). As already recognisable by eye, the catalytic efficiency is higher for the BCA catalysed hydrolysis of $\mathbf{D C F H}_{\mathbf{2}}$-DA $\left(\approx 0.020 \mu \mathrm{M}^{-1} \mathrm{~min}^{-1}\right)$ than for the one of $\mathbf{D C F H}_{2}$-MA $\left(\approx 0.001 \mu \mathrm{M}^{-1} \mathrm{~min}^{-1}\right)$. For more details about the determination of $k_{\text {cat }} / K_{\mathrm{M}}$ see the ESI, Table S$2 . \dagger$ The behaviour shown in Fig. 3 is very similar to what has been reported for the enzymatic hydrolysis of fluorescein diacetate and fluorescein di- $\beta$-D-galactopyranoside.$^{65,66}$

3.1.3. Hydrolysis of DCF-DA catalysed by BCA. Using DCFDA (Fig. S-2, ESI $\dagger$ ) - the oxidised form of $\mathbf{D C F H}_{2}-\mathbf{D A}$ - as substrate of BCA, the absorption spectrum of DCF-MA could be determined through manual fitting in the same way as in the case of DCFH $_{2}$-MA (see above). The spectrum is shown in Fig. 2B. The reaction which allowed determining the absorption spectrum of DCF-MA was carried out with $20 \mu$ M DCF-DA and $1.0 \mu \mathrm{M}$ BCA in PB ( $\mathrm{pH}=7.2,1$ vol\% DMSO) at $T=25^{\circ} \mathrm{C}$. Since there are two cleavable carboxylic acid ester bonds in DCF-DA, DCF-MA occurs as reaction intermediate, with DCF as final product. The changes in the absorption spectrum recorded during the reaction are shown in Fig. S-19, ESI. $\dagger$ Since DCF-DA has low solubility in aqueous solution, even in the presence of 1 vol\% DMSO, the reaction mixture at the start of the reaction was slightly turbid. However, the turbidity disappeared upon partial or complete DCF-DA hydrolysis. For a precise analysis of the reaction and for determining the absorption spectrum of DCF-MA by manual fitting, only the second phase of the reaction, starting at $t \approx 175 \mathrm{~min}$, was analysed, where turbidity did not exist anymore (increased water solubility of DCF-MA and DCF). The isosbestic points characterising the DCF-MA/DCF couple were found to be at $\lambda_{\text {iso }}=284,340$, and $460 \mathrm{~nm}$ (Table 1). Most precise and reliable were measurements of $A_{460}$, which allowed determining the total concentration of [DCF-MA] + $[\mathbf{D C F}]$. [DCF-MA $]+[\mathbf{D C F}]$ remained constant during the entire second phase of the reaction (only DCF-MA and DCF were
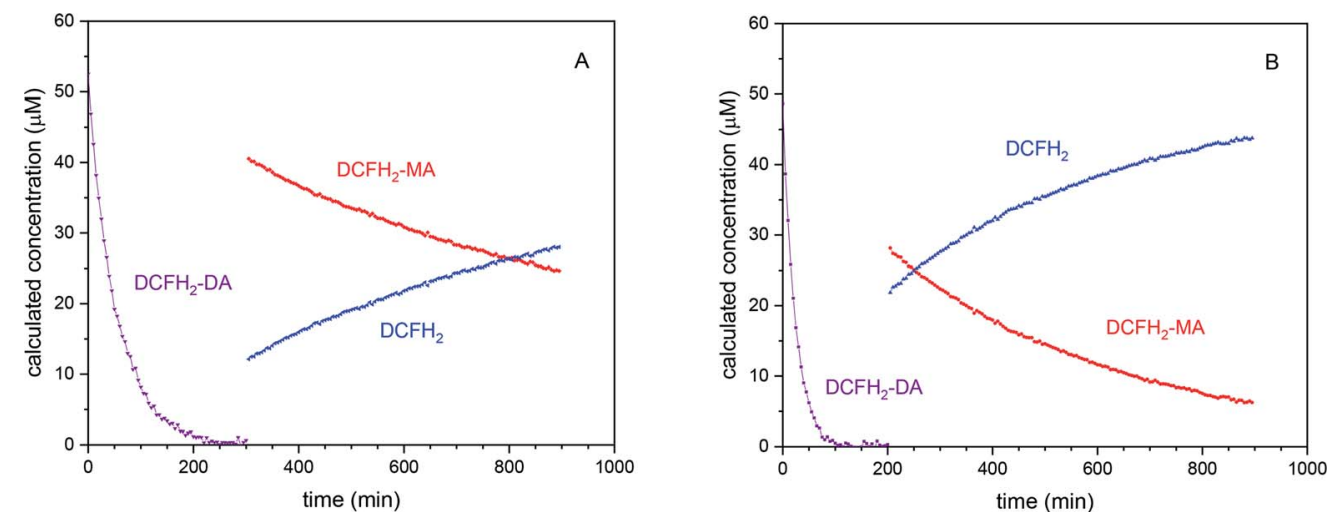

Fig. 3 Quantitative analysis of the BCA-catalysed hydrolysis of $\mathrm{DCFH}_{2}$-DA (50 $\mu \mathrm{M}, 1$ vol\% DMSO) in PB (10 mM sodium phosphate buffer solution, $\mathrm{pH}=7.2$ ) at $25^{\circ} \mathrm{C}$ with (A) $[\mathrm{BCA}]=1.0 \mu \mathrm{M}$ and (B) $[\mathrm{BCA}]=2.0 \mu \mathrm{M}$. The determination of the time-dependent decrease of [DCFH $\left.\mathrm{C}_{2}-\mathrm{DA}\right]$ at the beginning of the reaction and the time-dependent decrease of $\left[\mathrm{DCFH} \mathrm{H}_{2}-\mathrm{MA}\right]$ and increase of $\left[\mathrm{DCFH} \mathrm{H}_{2}\right]$ in the second phase of the reaction was achieved by taking into account the spectral changes shown in Fig. S-13 and S-14, ESI, $\uparrow$ and the absorption spectra of DCFH $-\mathrm{DA}_{2}, \mathrm{DCFH}-\mathrm{MA}_{2}$ and $\mathrm{DCFH}_{2}$ (Fig. 2A). For $[\mathrm{BCA}]=1.0 \mu \mathrm{M}$ and $t>300 \mathrm{~min}(\mathrm{~A})$, only $\mathrm{DCFH}_{2}-\mathrm{MA}$ and $\mathrm{DCFH}_{2}$ existed (second phase of the reaction). For $[\mathrm{BCA}]=2.0$ $\mu \mathrm{M}(\mathrm{B})$, the second phase of the reaction started at $t \approx 200 \mathrm{~min}$. For both reactions, [DCF] $(t=15 \mathrm{~h})<0.2 \mu \mathrm{M}$. For both hydrolysis steps the specificity constant $\left(k_{\text {cat }} / K_{M}\right)$ was determined showing a higher value for the initial hydrolysis of DCFH ${ }_{2}-\mathrm{DA}$ to DCFH ${ }_{2}-\mathrm{MA}$ (see Table S-2, ESI $\dagger$ ). 
present). A careful analysis of the spectra between $\lambda=400$ and $600 \mathrm{~nm}$ showed that for $\lambda>510 \mathrm{~nm}$ only DCF and $\mathbf{D C F}_{\mathbf{o x}}$ absorb light (Fig. S-19D, ESI $\dagger$ ). Since DCF $_{\mathbf{~ o x}}$ did not form in this reaction, the concentration of DCF during the second phase of the reaction could be quantified at any time point, and with this also the concentration as well as the absorption spectrum of the intermediate DCF-MA (Fig. 2B).

As for DCFH $_{2}$-DA and $\mathbf{D C F H}_{2}$-MA (see Section 3.1.2.), from the BCA-catalysed decrease of [DCF-MA], the kinetic efficiency $\left(k_{\text {cat }} / K_{\mathrm{M}}\right)$ was determined. It was $\approx 0.004 \mu \mathrm{M}^{-1} \mathrm{~min}^{-1}$, i.e., about four times higher than the one for its reduced analogue $(\approx 0.001$ $\mu \mathbf{M}^{-1} \min ^{-1}$ for $\mathbf{D C F H}_{2}$-MA) but still around 5-times lower than the one for $\mathbf{D C F H}_{2}$-DA $\left(\approx 0.020 \mu \mathrm{M}^{-1} \mathrm{~min}^{-1}\right)$. For more information about the determination of $k_{\text {cat }} / K_{\mathrm{M}}$, see the ESI, Table S$2 . \dagger$ As for the hydrolysis of the reduced form (DCFH $-\mathbf{D A}$, see above), the behaviour for DCF-DA shown in Fig. S-19C (ESI $\dagger$ ) is very similar to what has been reported for the enzymatic hydrolysis of fluorescein diacetate and fluorescein di- $\beta$-Dgalactopyranoside. ${ }^{65,66}$

3.1.4. Oxidation of $\mathrm{DCFH}_{2}$ catalysed by $\mathrm{HRP}$ and $\mathrm{H}_{2} \mathrm{O}_{2}$. Non-enzymatically prepared $\mathbf{D C F H}_{2}$ was incubated with HRP and $\mathrm{H}_{2} \mathrm{O}_{2}$ in $\mathrm{PB}(\mathrm{pH}=7.2)$ at $T=25^{\circ} \mathrm{C}$ in two different types of experiments (Fig. S-20, ESI $\dagger$ ).

In the first experiment, $50 \mu \mathrm{M} \mathbf{D C F H}_{2}$ were incubated with 0.5 $\mu \mathrm{M}$ HRP and $9 \mu \mathrm{M} \mathrm{H}_{2} \mathrm{O}_{2}$ altogether and the change of the absorption spectrum was recorded at $t=2,4$, and 15 min after preparing the reaction mixture (Fig. S-20A, ESI $\dagger$ ). The conditions were $\left[\mathbf{D C F H}_{2}\right]_{0}>2 \cdot\left[\mathrm{H}_{2} \mathrm{O}_{2}\right]_{0}$, which resulted in a rapid oxidation of a fraction of the initially present $\mathbf{D C F H}_{2}$ into DCF $(18 \mu \mathrm{M})$. Formation of $18 \mu \mathrm{M}$ DCF with $9 \mu \mathrm{M} \mathrm{H}_{2} \mathrm{O}_{2}$ and $0.5 \mu \mathrm{M}$ HRP is in agreement with what one expects from the oxidation step Oxi_1 of Scheme 1 (formation of two DCFH' intermediates for each $\mathrm{H}_{2} \mathrm{O}_{2}$ molecule via step Oxi_1', with subsequent non-enzymatic oxidation of DCFH' to DCF with $\mathrm{O}_{2}$ via step Oxi_1"). Under the conditions of the experiments $([\mathrm{HRP}]=0.5 \mu \mathrm{M})$ there was no proof for obtaining $\mathrm{H}_{2} \mathrm{O}_{2}$ from the formed superoxide radical anion $\left(\mathrm{O}_{2}{ }^{-}\right)$in step Oxi_1". It may well be that $\mathrm{O}_{2}{ }^{--}$reacted with some of the functional groups present in $\mathrm{HRP}^{67-69}$ or it reacted with water to form hydroperoxyl radicals and hydroxide ions $\left(\mathrm{O}_{2}{ }^{-}+\mathrm{H}_{2} \mathrm{O} \rightarrow \mathrm{HO}_{2}^{-}+\mathrm{HO}^{-}, \mathrm{p} K_{\mathrm{a}}\left(\mathrm{HO}_{2}\right) \approx 4.8\right) .^{67}$

In the second experiment, $10 \mu \mathrm{M}$ DCFH 2 were first added stepwise (over $4 \mathrm{~min}$ ) to $0.5 \mu \mathrm{M} \mathrm{HRP}$ and $9 \mu \mathrm{M} \mathrm{H}_{2} \mathrm{O}_{2}$, and the change of the absorption spectrum was measured until a stable spectrum was reached (after $t=8 \mathrm{~min}$, see Fig. S-20B, ESI $\dagger$ ). The conditions were $\left[\mathbf{D C F H}_{2}\right]_{0}<2 \cdot\left[\mathrm{H}_{2} \mathrm{O}_{2}\right]_{0}$ until $t=8 \mathrm{~min}$. After $t=$ $15 \mathrm{~min}$, additional $40 \mu \mathbf{M} \mathbf{D C F H}_{2}$ were added to the reaction mixture, without any significant change of the absorption spectrum between $\lambda=330$ and $600 \mathrm{~nm}$. This indicates that there was no $\mathrm{H}_{2} \mathrm{O}_{2}$ left that could activate HRP for oxidising the newly added $\mathbf{D C F H} \mathbf{H}_{2} \cdot{ }^{70}$ All $\mathrm{H}_{2} \mathrm{O}_{2}$ molecules were used up during the first $8 \mathrm{~min}$, resulting in a partial overoxidation of DCF (step Oxy_3 in Scheme 1), i.e., formation of $\mathbf{D C F}_{\mathbf{o x}}$ with a decreased absorption intensity at $\lambda=503 \mathrm{~nm}$ and a characteristic absorbance increase between $\lambda \approx 530$ and $540 \mathrm{~nm}$ (see above, Section 3.1.1.). $\mathrm{H}_{2} \mathrm{O}_{2}$ may also be oxidized to $\mathrm{O}_{2}$ and $\mathrm{H}_{2} \mathrm{O}$ via the catalatic cycle of HRP (see 3.1.1.). ${ }^{62,63}$ In this second experiment, $A_{503}$ remained much lower than in the case of the first experiment
$\left(A_{503}=0.61\right.$ vs. $\left.A_{503}=1.83\right)$, despite the final concentrations of all added reacting molecules and HRP were the same for both reactions (Fig. S-20, ESI $\dagger$ ). This clearly shows that irreversible DCF overoxidation is expected to occur in the presence of HRP only if (transient) conditions exist at which $\mathrm{H}_{2} \mathrm{O}_{2}$ is in excess over $\mathbf{D C F H}_{2}$ (conditions of the second experiment). ${ }^{71}$ Besides DCF overoxidation, catalatic $\mathrm{H}_{2} \mathrm{O}_{2}$ decomposition occurred under our conditions in a similar time scale (see Fig. S-9, ESI $\dagger$ ).

An important conclusion drawn from the two experiments is that the consumption of $\mathrm{H}_{2} \mathrm{O}_{2}$ in the presence of HRP and $\mathbf{D C F H}_{2}$ is due to a competition between (i) $\mathbf{D C F H} \mathbf{H}_{2}$ oxidation (resulting in DCF formation), (ii) DCF overoxidation, and (iii) catalatic $\mathrm{H}_{2} \mathrm{O}_{2}$ decomposition. The individual contributions by these competitive reactions depend in a complex manner on the concentrations of $\mathbf{D C F H}_{2}, \mathrm{H}_{2} \mathrm{O}_{2}$, and HRP.

3.1.5. UV/vis absorption spectra of all components of the cascade reaction. The UV/vis absorption spectra of all components of the cascade reaction, dissolved in $\mathrm{PB}$ at $\mathrm{pH}=7.2$ and $T$ $=25{ }^{\circ} \mathrm{C}$, are shown in Fig. S-6, ESI, $\dagger$ and Fig. 2, as obtained by either recording the corresponding spectra of those components that were commercially available in high purity (BCA, HRP, DCFH $\mathbf{H}_{2}$-DA, DCF, $\mathrm{H}_{2} \mathrm{O}_{2}$ ) or non-enzymatically synthesised $\left(\mathbf{D C F H}_{2}\right)$. The spectra of $\mathbf{D C F H} \mathbf{H}_{\mathbf{2}}$-MA and DCF-MA were determined by manual fitting. For each component, the wavelength dependence of the molar absorption is given in Table S-1, ESI, $\uparrow$ with important isosbestic points summarised in Table 1. Some of the key conclusions from Fig. 2 that are relevant for understanding the cascade reaction (Section 3.1.6.) are the following. (i) The most useful wavelength region for a quantitative analysis of the oxidised species in the reaction mixtures is between $\lambda=$ 330 and $550 \mathrm{~nm}$; (ii) for $\lambda>330 \mathrm{~nm}$ there is no absorption from reduced species $\left(\mathbf{D C F H}_{2}-\mathbf{D A}, \mathbf{D C F H}_{2}-\mathbf{M A}\right.$, or $\left.\mathbf{D C F H}_{2}\right)$; (iii) absorption at $\lambda=550 \mathrm{~nm}$ originates from $\mathbf{D C F}_{\mathbf{o x}}$ only; (iv) absorption at $\lambda=503 \mathrm{~nm}$ originates mainly from DCF and $\mathbf{D C F}_{\mathbf{~ o x}}$ (contribution from DCF-MA is negligible); and (v) in the absence of overoxidation (no $\mathbf{D C F}_{\mathbf{o x}}$ formation), $A_{460}$ is proportional to [DCF-MA $]+[\mathbf{D C F}]$.

3.1.6. Cascade reaction run under different initial conditions. The cascade reaction was investigated in PB (1 vol\% DMSO, $\mathrm{pH}=7.2$ ) at $T=25{ }^{\circ} \mathrm{C}$ for different initial conditions. In all cases, DCFH $\mathbf{H}_{2}$-DA, HRP, BCA, and $\mathrm{H}_{2} \mathrm{O}_{2}$ were mixed at the beginning of the reaction. Moreover, the initial concentration of DCFH $_{2}$-DA $\left(\left[\mathbf{D C F H}_{2} \text {-DA }\right]_{0}=50 \mu \mathrm{M}\right)$ was kept constant for all measurements, with variations of $[\mathrm{BCA}]$, [HRP], or $\left[\mathrm{H}_{2} \mathrm{O}_{2}\right]_{0}$. UV/ vis absorption spectra were recorded at predetermined time intervals between $\lambda=240$ and $600 \mathrm{~nm}$ for a total reaction time of $15 \mathrm{~h}$ (900 $\mathrm{min})$. In the following, the obtained results will be presented by (i) first focussing on spectral changes caused by variation of the initial concentration of one of the starting components of the cascade reaction (as shown in Fig. 4-8). Then, (ii) resulting trends are summarised and discussed regarding kinetic reaction course (pathways), product distribution at reaction equilibrium, and quantitative analysis of the cascade reaction.

(i) Obtained results based on analysing spectral changes.

Cascade reaction 1 with $\left[\mathbf{D C F H} \boldsymbol{H}_{2}-\mathbf{D A}\right]_{o}=50 \mu \mathrm{M},[B C A]=1.0$ $\mu M,[H R P]=0.5 \mu M$, and $\left[\mathrm{H}_{2} \mathrm{O}_{2}\right]_{o}=9 \mu M$. This reaction was 

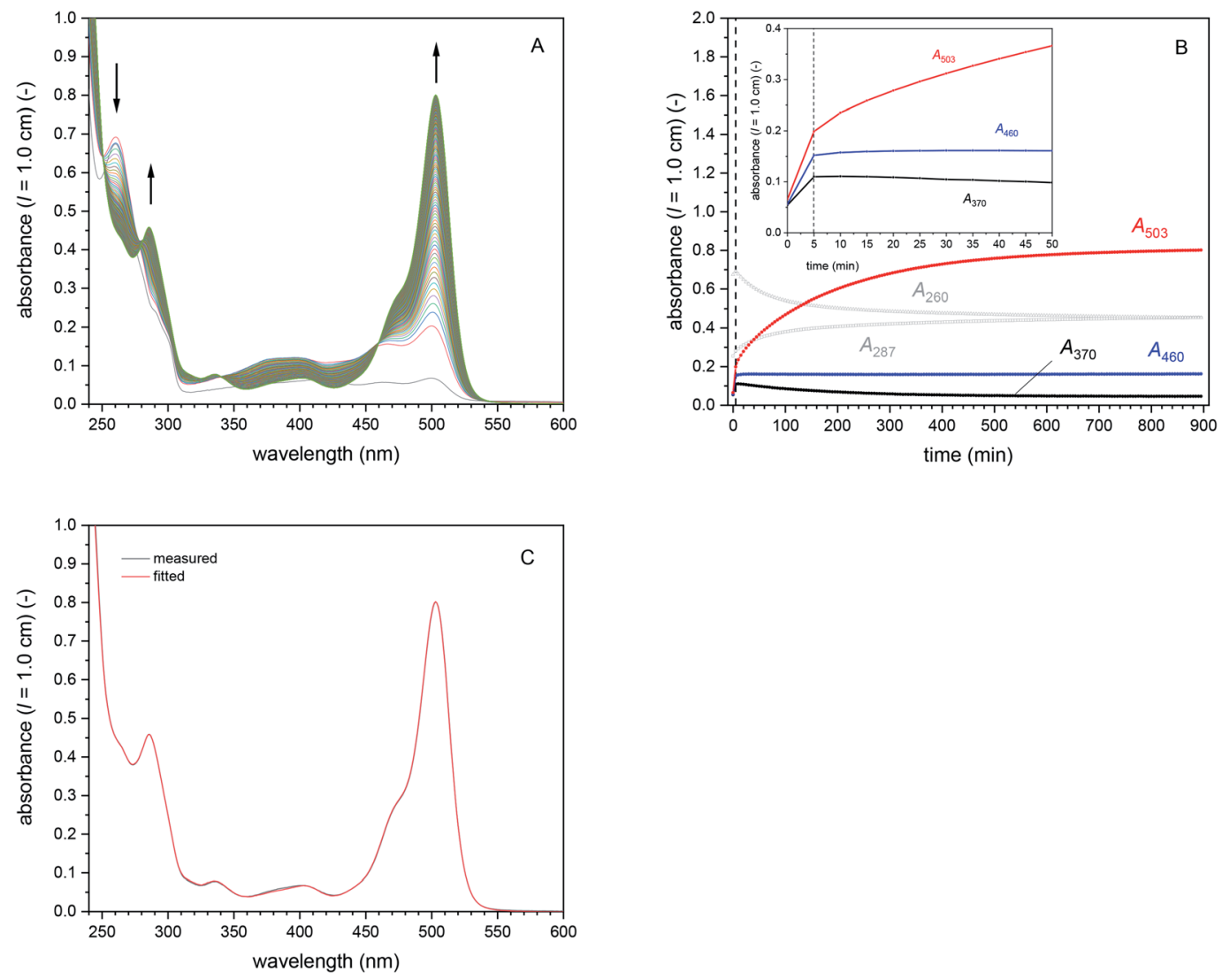

Fig. 4 Cascade reaction 1 (in bulk solution) with $\left[\mathrm{DCFH} \mathrm{H}_{2}-\mathrm{DA}\right]_{0}=50 \mu \mathrm{M},[\mathrm{BCA}]=1.0 \mu \mathrm{M},[\mathrm{HRP}]=0.5 \mu \mathrm{M}$, and $\left[\mathrm{H}_{2} \mathrm{O}_{2}\right]_{0}=9 \mu \mathrm{M}, \mathrm{PB}(\mathrm{pH}=7.2)$, 1 vol\% DMSO, $T=25^{\circ} \mathrm{C}$. (A) Changes in the UV/vis absorption spectrum, recorded every $5 \mathrm{~min}$ for $15 \mathrm{~h}$. Besides the growing peak at $\lambda=503 \mathrm{~nm}$ (mainly originating from DCF), $\lambda_{\text {iso }}$ (DCF-MA/DCF) at 340 and $460 \mathrm{~nm}$ can easily be seen (formed after $t \approx 5 \mathrm{~min}$ ). (B) Changes of $A_{260}, A_{287}, A_{370}$, $A_{460}$, and $A_{503}$ during the reaction, up to $t=15 \mathrm{~h}$ (inset: zoom-in for the first $50 \mathrm{~min}$ ). After $t=5 \mathrm{~min}$ (dashed vertical line), most of the added $\mathrm{H}_{2} \mathrm{O}_{2}$ was consumed, disabling any further HRP-catalysed oxidation reactions. Therefore, only BCA-catalysed hydrolysis reactions could take place. Hydrolysis of DCF-MA to DCF is evident in the region of the spectrum in which the reduced species do not absorb $(\lambda=330-600 \mathrm{~nm})$ : increase of $A_{503}$, decrease of $A_{370}$ (DCF-MA), with a stable value of $A_{460}$. DCF $F_{\text {ox }}$ only formed within the first 5 min (presumably with concomitant HRPcatalysed catalatic $\mathrm{H}_{2} \mathrm{O}_{2}$ decomposition, see Fig. S-9, ESI + ). (C) Comparison of the spectrum measured after $t=15 \mathrm{~h}$ (black line) with the sum of the spectra obtained by fitting (red line). The fitted concentrations of the individual species present in the reaction mixture after $t=15 \mathrm{~h}$ are given in Table S-3. $\dagger[\mathrm{BCA}]=1.0 \mu \mathrm{M} ;[\mathrm{HRP}]=0.5 \mu \mathrm{M} ;[\mathrm{DCFH} 2-\mathrm{DA}]=0 \mu \mathrm{M} ;[\mathrm{DCFH}-\mathrm{MA}]=9.5 \mu \mathrm{M} ;\left[\mathrm{DCFH} \mathrm{H}_{2}\right]=30.9 \mu \mathrm{M} ;[\mathrm{DCF}-\mathrm{MA}]=0 \mu \mathrm{M} ;[\mathrm{DCF}]=7.6$ $\mu \mathrm{M} ;\left[\mathrm{DCF}_{\mathrm{ox}}\right]=1.0 \mu \mathrm{M}$.

considered as "standard reaction" in bulk solution. All further reactions were systematic deviations for this standard reaction, whereby only the concentration of one of the four components was changed at a time. The progress of the standard reaction is shown in Fig. 4A and B. Clear changes in the spectrum with increasing reaction time were (i) a decrease in $A_{260}$ and an increase in $A_{287}$ (originating from the hydrolysis of $\mathbf{D C F H}-\mathbf{D A}$ ); and (ii) the appearance of a band at $\lambda_{\max }=503 \mathrm{~nm}$ (originating predominantly from the formation of DCF and only to a small extent from $\mathbf{D C F}_{\mathbf{o x}}$, the latter if oxidation of DCF occurred). $A_{460}$, the absorbance measured at $\lambda_{\text {iso }}$ (DCF-MA/DCF), increased during the first $5 \mathrm{~min}$ and then remained almost constant. This indicates that after $t=5 \mathrm{~min},[\mathbf{D C F}-\mathbf{M A}]+[\mathbf{D C F}]\left(+\left[\mathbf{D C F}_{\mathbf{o x}}\right]\right)$ remained practically unchanged. At $t \approx 5 \mathrm{~min}$, $\mathbf{D C F H}_{2}$-DA was still being hydrolysed but no oxidation reaction was observed anymore. This indicates complete consumption of $\mathrm{H}_{2} \mathrm{O}_{2}$ within the first $5 \mathrm{~min}$. The increase in $A_{503}$ for $t>5 \mathrm{~min}$ reflects the formation of DCF at the expenses of DCF-MA. ${ }^{72}$ After $t=15 \mathrm{~h}$, no significant amounts of DCF-MA anymore, but small quantities of $\mathbf{D C F}_{\mathbf{o x}}$ were observed (see below).

The spectrum measured after $t=15 \mathrm{~h}$ is shown in Fig. 4C and was fitted with the reference spectra shown in Fig. S-6, ESI, $\dagger$ and Fig. 2, by taking into account information from isosbestic points $\left(\lambda_{\text {iso }}\right.$, see Table 1$)$ and characteristic absorptions (e.g. $A_{503}$ for DCF or $A_{550}$ for $\left.\mathbf{D C F}_{\mathbf{o x}}\right)$ : [ $\left.\mathbf{D C F H}_{2}-\mathbf{D A}\right]=0 \mu \mathrm{M},\left[\mathbf{D C F H}_{2}-\mathbf{M A}\right]=$ $11.5 \mu \mathrm{M},\left[\mathbf{D C F H}_{2}\right]=30.9 \mu \mathrm{M},[\mathbf{D C F}-\mathbf{M A}]=0 \mu \mathrm{M},[\mathbf{D C F}]=7.6 \mu \mathrm{M}$, and $\left[\mathbf{D C F}_{\mathbf{o x}}\right]=1.0 \mu \mathrm{M}$, see Table S-3, ESI. $\dagger$ Such compound concentration determinations were also made for the following cascade reactions $2-4$ (see Table S-3, ESI $\dagger$ ).

Cascade reactions 2 with $\left[\mathbf{D C F H} \mathbf{H}_{2}-\mathbf{D A}\right]_{o}=50 \mu \mathrm{M},[\mathrm{HRP}]=0.5$ $\mu M,\left[\mathrm{H}_{2} \mathrm{O}_{2}\right]_{o}=9 \mu M$, and $[B C A]=0-3.0 \mu M$. In Fig. 5, the timedependent changes in $A_{503}$ and $A_{460}$ are shown for the cascade reaction with the different BCA concentrations used $(0,0.5,1.0$, 2.0, and $3.0 \mu \mathrm{M})$. There are two main observations. First, the higher the BCA concentration was, the faster was the increase in $A_{503}$ and the higher was $A_{503}$ after $t=15 \mathrm{~h}$. However, $A_{503}(t=15$ 

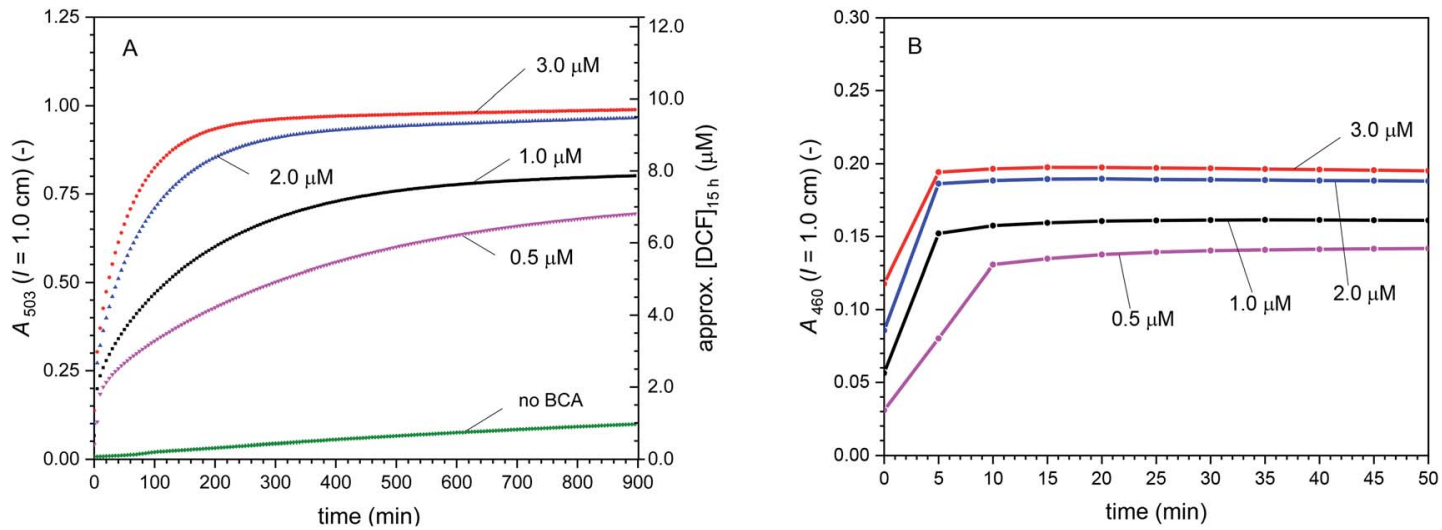

Fig. 5 Cascade reaction 2 (in bulk solution) with $\left[\mathrm{DCFH} \mathrm{H}_{2}-\mathrm{DA}\right]_{0}=50 \mu \mathrm{M},[\mathrm{HRP}]=0.5 \mu \mathrm{M},\left[\mathrm{H}_{2} \mathrm{O}_{2}\right]_{0}=9 \mu \mathrm{M}$, and $[\mathrm{BCA}]=0-3.0 \mu \mathrm{M}, \mathrm{PB}(\mathrm{pH}=7.2)$, $1 \mathrm{vol} \% \mathrm{DMSO}, T=25^{\circ} \mathrm{C}$. (A) Changes of $A_{503}$ with time up to $t=15 \mathrm{~h}$. (B) Changes of $A_{460}$ with time for the first 50 min. After an initial increase with time, $A_{460}$ did not change anymore after a few minutes. This indicates that all oxidation reactions completed within the first few minutes. The continued increase in $A_{503}$ was due to hydrolysis of DCF-MA to DCF. In (A), the approximate concentration of DCF after $t=15 \mathrm{~h}$ is given on the right hand side (on the simple basis of $A_{503}$, ignoring the much smaller contribution of DCF ox to $A_{503}$ ), see Table S-3 (ESI $\uparrow$ ) for the more elaborate concentrations of all the different species in the reaction mixture, as obtained by spectral fitting.
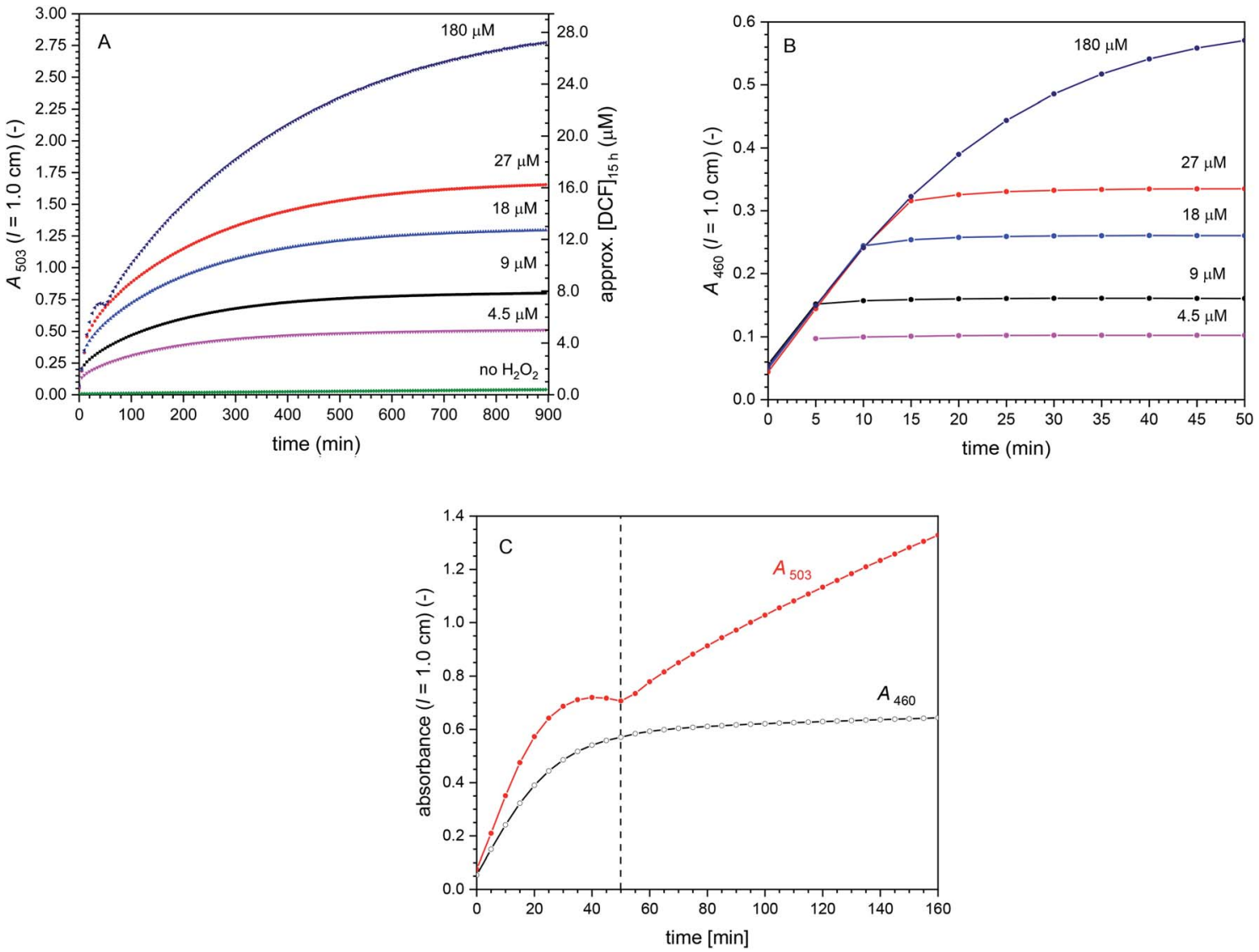

Fig. 6 Cascade reactions 3 (in bulk solution) with $\left[\mathrm{DCFH} \mathrm{H}_{2}-\mathrm{DA}\right]_{0}=50 \mu \mathrm{M},[\mathrm{BCA}]=1.0 \mu \mathrm{M},[\mathrm{HRP}]=0.5 \mu \mathrm{M}$, and $\left[\mathrm{H}_{2} \mathrm{O}_{2}\right]_{0}=0-180 \mu \mathrm{M}, \mathrm{PB}(\mathrm{pH}=$ 7.2), 1 vol\% DMSO, $T=25^{\circ} \mathrm{C}$. (A) Changes of $A_{503}$ with time up to $t=15 \mathrm{~h}$. (B) Changes of $A_{460}$ with time for the first 50 min. With the exception of $\left[\mathrm{H}_{2} \mathrm{O}_{2}\right]_{0}=180 \mu \mathrm{M}$, after an initial increase with time, $A_{460}$ did not change anymore after a few minutes (all added $\mathrm{H}_{2} \mathrm{O}_{2}$ reacted). This indicates that in these cases, all oxidation reactions completed within the first few minutes. (C) Zoom-in for data obtained for $\left[\mathrm{H}_{2} \mathrm{O}_{2}\right]_{0}=180 \mu M$ for up to $t=$ $160 \mathrm{~min}$. The observed change of $A_{503}$ during the first $50 \mathrm{~min}$ appears strange, but can be explained by fast oxidation of $\mathrm{DCF}$ to $\mathrm{DCF}$ ox $(\mathrm{see}$ text). Although such overoxidation leads to a decrease in $A_{460}$, the observed increase in $A_{460}$ indicates DCF-MA was still formed during this time period. Moreover, oxidation reactions with $\left[\mathrm{H}_{2} \mathrm{O}_{2}\right]_{0}=180 \mu \mathrm{M}$ occurred beyond 50 min, reaching a stable value of $A_{460}$ only after $t \approx 200$ min (not shown). For all $\mathrm{H}_{2} \mathrm{O}_{2}$ concentrations, the initial rate of DCF-MA/DCF formation ( $d A_{460} / \mathrm{d} t$ ) was the same. The continued increase in $A_{503}$ was due to hydrolysis of DCF-MA to DCF. In (A), the approximate concentration of DCF after $t=15 \mathrm{~h}$ is given on the right hand side (on the simple basis of $A_{503}$, ignoring the much smaller contribution of $\mathrm{DCF}_{\mathrm{ox}}$ to $\left.A_{503}\right)$, see Table S-3 (ESI $\dagger$ ) for the more elaborate concentrations of all the different species in the reaction mixture, as obtained by spectral fitting. 
h) did not correlate linearly with [BCA] (Fig. 5A). The timedependent change of $A_{460}$ shows that for all cases, the oxidation reactions were completed after a few minutes, after which a stable value of $A_{460}$ was reached (Fig. 5B), while $A_{503}$ still continued to increase (Fig. 5A). Second, the higher the BCA concentration was, the higher $[\mathbf{D C F}-\mathbf{M A}]+[\mathbf{D C F}]$, i.e., higher values of $A_{460}$ were obtained (Fig. 5B). With this, the higher the BCA concentration was, the lower the amount of overoxidised products $\left(\mathbf{D C F}_{\mathbf{o x}}\right)$ formed, see Table S-3, ESI. $\uparrow$ The BCA-catalysed hydrolysis reactions clearly were rate limiting. During the second phase of the reaction, after $A_{460}$ was constant, only hydrolysis of DCF-MA to DCF took place $\left(\lambda_{\text {iso }}(\right.$ DCF-MA/DCF $)=$ $460 \mathrm{~nm}$, Table 1). For the compound concentrations at $t=15 \mathrm{~h}$, see Table S-3, ESI. $\dagger$

Cascade reactions 3 with $\left[\mathbf{D C F} \boldsymbol{H}_{2}-\mathbf{D A}\right]_{o}=50 \mu M,[B C A]=1.0$ $\mu M,[H R P]=0.5 \mu M,\left[\mathrm{H}_{2} \mathrm{O}_{2}\right]_{o}=0-180 \mu M$. The effect of varying the initial $\mathrm{H}_{2} \mathrm{O}_{2}$ concentration on the cascade reaction is shown in Fig. 6, illustrated by plotting $A_{503}$ (Fig. 6A) and $A_{460}$ (Fig. 6B) vs. reaction time for $\left[\mathrm{H}_{2} \mathrm{O}_{2}\right]_{0}=4.5,9.0,18,27$ and $180 \mu \mathrm{M}$ (arbitrarily chosen). Interestingly, the initial rate of increase of $A_{460}$ was the same for all $\left[\mathrm{H}_{2} \mathrm{O}_{2}\right]_{0} \geq 9.0 \mu \mathrm{M}$ - and it was probably also the same for $\left[\mathrm{H}_{2} \mathrm{O}_{2}\right]_{0}=4.5 \mu \mathrm{M}$, although we do not have spectral data for $t<5 \mathrm{~min}$, i.e., for the very early phase of the reaction. After $t=50 \mathrm{~min}$ or less, depending on $\left[\mathrm{H}_{2} \mathrm{O}_{2}\right]_{0}, A_{460}$ remained constant, while $A_{503}$ continued to increase. This shows again that all oxidation reactions were completed during the initial phase of the reaction, resulting in a complete consumption of the initially added $\mathrm{H}_{2} \mathrm{O}_{2}$. The changes that occurred after this initial phase were due to hydrolysis of DCFMA to DCF (Hyd_3 in Scheme 2). Worth noting is the case of $\left[\mathrm{H}_{2} \mathrm{O}_{2}\right]_{0}=180 \mu \mathrm{M}$ (Fig. 6C). After an initial increase of $A_{503}$ with reaction time, $A_{503}$ started to slightly decrease at $t=40-50 \mathrm{~min}$ before it increased again. This behaviour was due to the overoxidation of DCF (formation of $\mathbf{D C F}_{\mathbf{o x}}$ ) between $t=40$ and $50 \mathrm{~min}$ (which is pronounced for such high $\mathrm{H}_{2} \mathrm{O}_{2}$ concentration
$\left.\left(2\left[\mathrm{H}_{2} \mathrm{O}_{2}\right]_{0} \gg\left[\mathbf{D C F H}_{2} \text {-DA }\right]_{0}\right)\right)$. The $\mathrm{HRP} / \mathrm{H}_{2} \mathrm{O}_{2}$-catalysed formation of $\mathbf{D C F}_{\mathbf{o x}}$ was faster than the DCF formation in that period. Since $A_{460}$ was still increasing, DCF-MA was still being formed. For the compound concentrations at $t=15 \mathrm{~h}$, see Table S-3, ESI. $\dagger$

Cascade reactions 4 with $\left[\mathbf{D C F H} \boldsymbol{H}_{2}-\mathbf{D A}\right]_{o}=50 \mu M,[B C A]=1.0$ $\mu M,\left[\mathrm{H}_{2} \mathrm{O}_{2}\right]_{o}=9 \mu \mathrm{M},[\mathrm{HRP}]=0-1.50 \mu \mathrm{M}$. For this series of cascade reactions with variation of the HRP concentration, from as low as $2.5 \mathrm{nM}$ to as high as $1.5 \mu \mathrm{M}$, a seemingly strange behaviour is observed if $A_{503}$ is plotted $v s$. reaction time (Fig. 7A). However, the situation becomes clear if instead of $A_{503}$, the absorbance at $\lambda_{\text {iso }}$ (DCF-MA/DCF), $A_{460}$, is considered (Fig. 7B).

For $[\mathrm{HRP}]=0.25-1.50 \mu \mathrm{M}$, all oxidation reactions were completed within the first few minutes $(t<20 \mathrm{~min})$, after which $A_{460}$ did not change anymore (Fig. 7B, inset). Analysis of $\mathrm{d} A_{460} / \mathrm{d} t$ for the first $5 \mathrm{~min}$ showed that the rate of [DCF-MA $]+[\mathbf{D C F}]$ formation (slightly) decreased with increasing HRP concentration. As (for a high HRP concentration) BCA-catalysed $\mathbf{D C F H}_{2}$ DA hydrolysis was the rate limiting step for DCF-MA/DCF formation (see above reactions 2) and $\left[\mathrm{H}_{2} \mathrm{O}_{2}\right]$ for the largest part did not affect $\mathrm{d} A_{460} / \mathrm{d} t$ (see above reactions 3), using more HRP did probably simply support DCF overoxidation and catalatic $\mathrm{H}_{2} \mathrm{O}_{2}$ decomposition in this case.

For $[\mathrm{HRP}]=2.5-7.5 \mathrm{nM}$, the oxidation reactions were completed after much longer time than in the case of [HRP] $=$ 0.25-1.50 $\mu \mathrm{M}$ : after $450 \mathrm{~min}$ for $[\mathrm{HRP}]=7.5 \mathrm{nM}$, or after $650 \mathrm{~min}$ for $[\mathrm{HRP}]=5.0 \mathrm{nM}$. In this case, the slow $\mathrm{HRP} / \mathrm{H}_{2} \mathrm{O}_{2}$ catalysed oxidation of $\mathbf{D C F H}_{2}$-MA and $\mathbf{D C F H}_{2}$ to DCF-MA and DCF was rate limiting, thereby suppressing overoxidation; $\mathrm{d} A_{460} / \mathrm{d} t$ was directly proportional to [HRP]. With the oxidation being the rate limiting step, $\mathbf{D C F H}_{2}-\mathbf{M A}$ and $\mathbf{\mathbf { D C F H } _ { 2 }}$ formed faster than they were further oxidised. For the compound concentrations at $t=15 \mathrm{~h}$, see Table S-3, ESI. $\dagger$
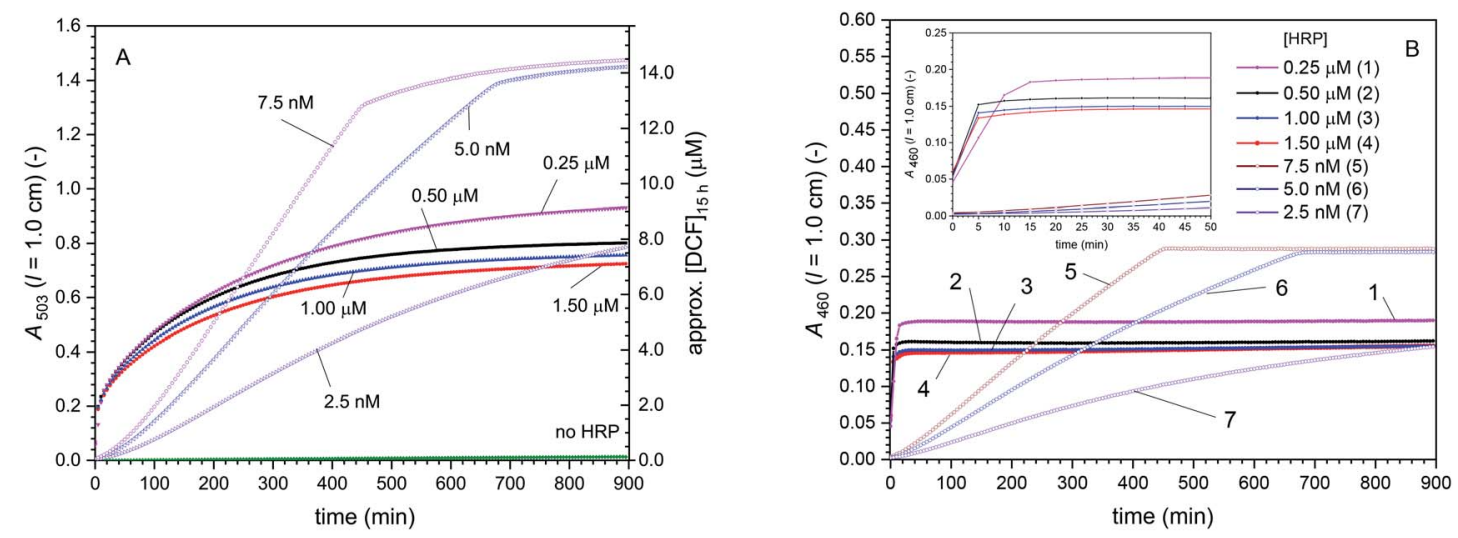

Fig. 7 Cascade reaction 4 (in bulk solution) with $\left[\mathrm{DCFH} \mathrm{H}_{2}-\mathrm{DA}\right]_{0}=50 \mu \mathrm{M},[\mathrm{BCA}]=1.0 \mu \mathrm{M},\left[\mathrm{H}_{2} \mathrm{O}_{2}\right]_{0}=9 \mu \mathrm{M}$, and $[\mathrm{HRP}]=0-1.50 \mu \mathrm{M}, \mathrm{PB}(\mathrm{pH}=7.2)$, $1 \mathrm{vol} \% \mathrm{DMSO}, T=25^{\circ} \mathrm{C}$. Changes of $A_{503}(\mathrm{~A})$ and $A_{460}$ (B) with time for up to $t=15 \mathrm{~h}$ (inset: zoom-in for the first $50 \mathrm{~min}$ ). For [HRP] $=0.25-1.50$ $\mu \mathrm{M}$, all oxidation reactions (see Scheme 2 ) were finished during the first few minutes. For $[\mathrm{HRP}]=2.5-7.5 \mathrm{nM}$, the oxidation reactions were slow, as indicated by the slow increase in $A_{460}$ with time (slow consumption of $\mathrm{H}_{2} \mathrm{O}_{2}$, suppressing overoxidation, i.e., prevention of DCF ox formation. $\mathrm{HRP}$ being rate limiting presumably also suppressed catalatic $\mathrm{H}_{2} \mathrm{O}_{2}$ decomposition to a big extent). In (A), the approximate concentration of DCF after $t=15 \mathrm{~h}$ is given on the right hand side (calculated on the basis of $A_{503}$, ignoring the much smaller contribution of $\mathrm{DCF}_{\mathrm{ox}}$ to $A_{503}$ ). The lower $[\mathrm{HRP}]$ was, the more negligible the extent of overoxidation was, and thus the more precise is the approximation. See Table S-3 (ESI) $\uparrow$ for the more elaborate concentrations of all the different species in the reaction mixture, as obtained by spectral fitting. 

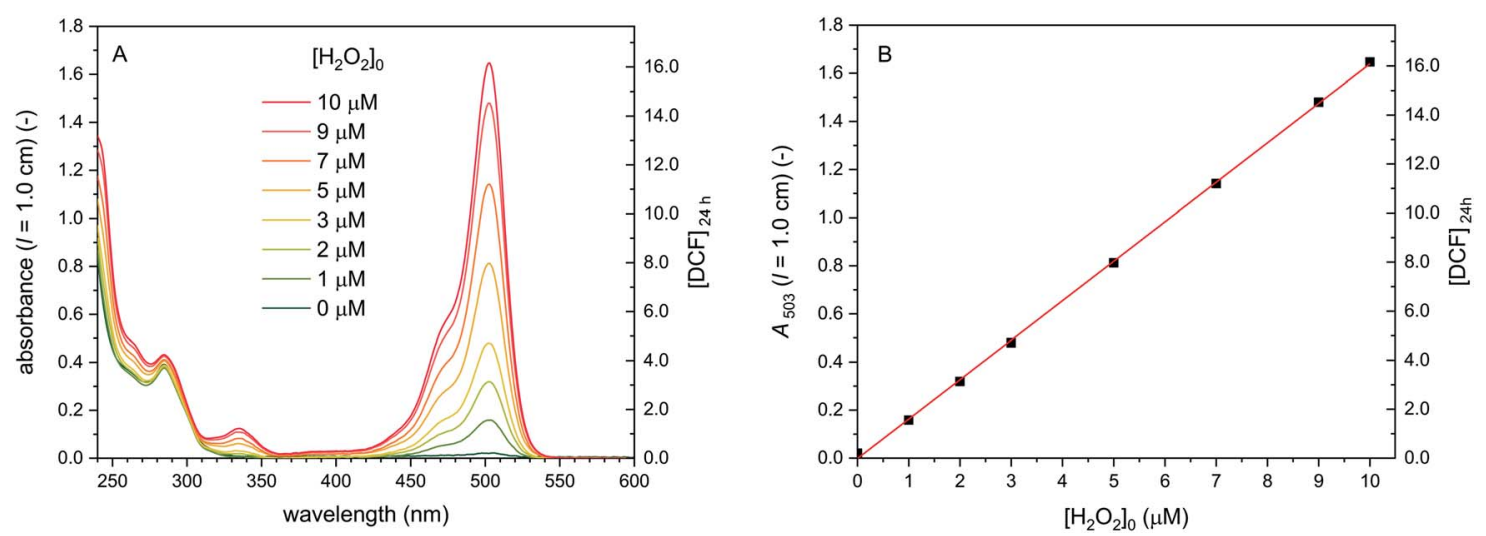

Fig. 8 Cascade reactions 5 (in bulk solution) with $\left[\mathrm{DCFH} \mathrm{H}_{2}-\mathrm{DA}\right]_{0}=50 \mu \mathrm{M},[\mathrm{BCA}]=1.0 \mu \mathrm{M},[\mathrm{HRP}]=10 \mathrm{nM}, \mathrm{and}\left[\mathrm{H}_{2} \mathrm{O}_{2}\right]_{0}=0-10 \mu \mathrm{M}, \mathrm{PB}(\mathrm{pH}=7.2)$, $1 \mathrm{vol} \% \mathrm{DMSO}, T=25^{\circ} \mathrm{C}$. (A) UV/vis spectrum of the reaction mixtures measured after $t=24 \mathrm{~h}$. (B) $A_{503}(t=24 \mathrm{~h}) v \mathrm{~s}$. $\left[\mathrm{H}_{2} \mathrm{O}_{2}\right]_{0}$. The concentration of DCF obtained after $t=24 \mathrm{~h}$ is shown on the right hand side. Spectral fitting showed that $\mathrm{DCF}_{\mathrm{ox}}$ did not form. Linear regression for the data points for $\left[\mathrm{H}_{2} \mathrm{O}_{2}\right]_{0}=0-10 \mu \mathrm{M}$ is shown (coefficient of determination, $R^{2}=0.99969$ ).

Cascade reactions 5 with $\left[\mathbf{D C F H}_{2}-\mathbf{D A}\right]_{o}=50 \mu \mathrm{M},[\mathrm{BCA}]=1.0$ $\mu M,[H R P]=10 \mathrm{nM},\left[\mathrm{H}_{2} \mathrm{O}_{2}\right]_{o}=0-10 \mu \mathrm{M}$. The conditions for this last series of measurements in bulk solution were chosen on the basis of our analysis of cascade reactions 1-4 (Fig. 4-7 and ESI, Section $14 \dagger$ ). With the analysis carried out so far, it became clear how the initial bulk reaction conditions must be chosen for obtaining, for example, a linear correlation between $\left[\mathrm{H}_{2} \mathrm{O}_{2}\right]_{0}$ and $A_{503}$ for reaction times at which reaction equilibrium is approached $(t \approx 24 \mathrm{~h}$ ): the HRP-catalysed oxidation reactions must be rate limiting but still fast enough so that reaction equilibrium is reached within $24 \mathrm{~h}$. The results of the experiments run under such conditions are shown in Fig. 8. $A_{503}$ correlates linearly with $\left[\mathrm{H}_{2} \mathrm{O}_{2}\right]_{0}$, although for all initial $\mathrm{H}_{2} \mathrm{O}_{2}$ concentrations, the $\mathrm{H}_{2} \mathrm{O}_{2}$ conversion in terms of DCF formation was about $80 \%$. Since no $\mathbf{D C} \mathbf{F}_{\mathbf{o x}}$ formed under these conditions (verified by spectral fitting), the $20 \% \mathrm{H}_{2} \mathrm{O}_{2}$ conversion missing were most likely due to the catalatic activity of HRP. ${ }^{\mathbf{6 2 , 6 3}}$

(ii) Summary and discussion of observed trends upon variation of initial concentrations.

The most significant changes in the cascade reaction were observed upon varying [HRP], while keeping the concentrations of the other reaction components constant $\left(\left[\mathbf{D C F H}_{\mathbf{2}}-\mathbf{D A}\right]_{0}=50\right.$ $\mu \mathrm{M},[\mathrm{BCA}]=1 \mu \mathrm{M},\left[\mathrm{H}_{2} \mathrm{O}_{2}\right]_{0}=9 \mu \mathrm{M}$, see Fig. 7B). Adding HRP at comparatively low $([\mathrm{HRP}]=2.5-7.5 \mathrm{nM})$ or high concentration $([\mathrm{HRP}]=0.25-1.50 \mu \mathrm{M})$ determined whether the oxidation (Oxi_1 and Oxi_2, Scheme 2) or the hydrolysis (Hyd_1) was rate limiting for the combined formation of DCF + DCF-MA. In the following discussion, the rate of the combined formation of the oxidized species DCF + DCF-MA (directly proportional to $\mathrm{d} A_{460}$ / $\mathrm{d} t$ ) will be considered and not the rate of DCF formation only (proportional to $\mathrm{d} A_{503} / \mathrm{d} t$ ). The continuous hydrolysis of DCFMA (Hyd_3) turned out to stably yield DCF over time.

Under conditions at which oxidation was rate limiting for the combined formation of $\mathbf{D C F}+\boldsymbol{D C F}-\mathbf{M A}$. Under these conditions, $\mathrm{d} A_{460} / \mathrm{d} t$ was linearly dependent on [HRP]. Overoxidation ( $\mathbf{D C F}_{\mathbf{o x}}$ formation) was suppressed while catalatic $\mathrm{H}_{2} \mathrm{O}_{2}$ decomposition was minimized (see Section 3.1.4.). The suppression of these
$\mathrm{H}_{2} \mathrm{O}_{2}$ consuming side reactions allowed for a DCF formation linearly depending on $\left[\mathrm{H}_{2} \mathrm{O}_{2}\right]_{0}$ (see Fig. 8).

Under conditions at which hydrolysis was rate limiting for the combined formation of DCF + DCF-MA. Under conditions at which hydrolysis was rate limiting for the combined formation of DCF + DCF-MA, $\mathrm{d} A_{460} / \mathrm{d} t$ did not increase with increasing [HRP] (or $\left[\mathrm{H}_{2} \mathrm{O}_{2}\right]_{0}$, see Fig. 6B). Therefore, [HRP] and $\left[\mathrm{H}_{2} \mathrm{O}_{2}\right]_{0}$ were considered to be in "in excess" under these conditions. Thus, the initial hydrolysis of $\mathbf{D C F H}_{\mathbf{2}}$-DA (Hyd_1) was rate limiting. With [HRP] and $\left[\mathrm{H}_{2} \mathrm{O}_{2}\right]_{0}$ being "in excess", DCF formation and catalatic $\mathrm{H}_{2} \mathrm{O}_{2}$ decomposition gained significant contribution. Thereby, the formation of DCF was not linearly dependent on $\left[\mathrm{H}_{2} \mathrm{O}_{2}\right]_{0}$ anymore (see Table S-3, ESI $\dagger$ ).

Regarding the two reaction pathways (Scheme 2). Although a complete absence of one reaction pathway could never be observed, one of them dominated, depending on whether oxidation or hydrolysis was rate limiting for the combined formation of DCF + DCF-MA $\left(\mathrm{d} A_{460} / \mathrm{d} t\right)$. For conditions with rate limiting hydrolysis, pathway 2 was predominant. Since the oxidation of $\mathbf{D C F H}_{2}$-MA (Oxi_2) was much faster than its hydrolysis (Hyd_2) under these conditions, the concentration of DCFH $\mathbf{H}_{2}$ remained very low until most $\mathrm{H}_{2} \mathrm{O}_{2}$ was consumed. For conditions with rate limiting oxidation, the situation was more complex. Under these conditions, pathway 2 was predominant only at the beginning of the reaction, where $\left[\mathbf{D C F H}_{2}-\mathbf{M A}\right] \gg$ $\left[\mathbf{D C F H}_{2}\right]$ (see Fig. 3). Pathway 1 was gaining increasing contribution over time, as $\left[\mathbf{D C F H}_{2}\right]$ continuously increased. Interestingly, the ratio of DCF formed via pathway 1 to DCF formed via pathway 2 increased much faster with time than the ratio of the concentrations of $\mathbf{D C F H}_{2}$ to $\mathbf{D C F H}_{2}$-MA. This indicated that Oxi_1 > Oxi_2 (given the same [HRP] and $\left[\mathrm{H}_{2} \mathrm{O}_{2}\right]_{0}$ ). This relation could be confirmed, even for $\left[\mathbf{D C F H}_{2}\right]$ being one order of magnitude lower than [ DCFH $_{2}$-MA] (see Scheme S-1, ESI $\dagger$ ). As pathway 2 was predominant at the beginning of the reaction but pathway 1 became predominant relatively quickly, the reaction time determined which of the two pathways dominated. Overall, the experimental data fully confirm what one expects from Scheme 2: the higher the ratio of BCA to HRP, the higher the 
contribution from pathway 1 ; and the lower the reaction time, the higher the contribution from pathway 2 (see ESI Section 15 with Fig. S-21 and Scheme S-1†).

Regarding quantitative analysis of the cascade reaction. From all conditions under which the cascade reaction was investigated (cascade reactions 1-5), it became clear that the analysis of the cascade reaction was much more straightforward when the oxidation was rate limiting for the combined formation of DCF + DCF-MA $\left(\mathrm{d} A_{460} / \mathrm{d} t\right)$, as complicating side reactions were suppressed (overoxidation and catalatic $\mathrm{H}_{2} \mathrm{O}_{2}$ decomposition). The determination of $[\mathbf{D C F}]+[$ DCF-MA $]$ by measuring $A_{460}$ (at $\lambda_{\text {iso }}=460 \mathrm{~nm}$ ) turned out to be most useful for fully understanding the complex changes of $A_{503}$ occuring during the reaction. Following the reaction by monitoring $A_{503}$ only can be puzzling. Similarly, great care should be taken if the reaction is followed by fluorescence spectroscopy only, since with this only the formation of DCF is detected, without any quantitiative information about remaining DCF-MA or formed $\mathbf{D C F}_{\mathbf{o x}}$. In that case, wrong oxidation turnovers might be determined - even if DCF was quantified correctly - and wrong interpretations regarding e.g. catalyst activity or $\mathrm{H}_{2} \mathrm{O}_{2}$ concentration might be the consequences.

Based on the gained in-depth understanding, the cascade reaction using BCA and HRP was tunable to some extent (see e.g. cascade reactions 5, Fig. 8). More important for this work, however, the detailed analysis of the bulk solution reactions was essential for analysing the same cascade reaction run with immobilised BCA and HRP in a flow-through device, as discussed in the following sections.

\subsection{Immobilisation of BCA and HRP in glass fiber filters}

The two enzymes BCA and HRP were immobilised in borosilicate glass fiber filters with a methodology that has been elaborated before, see (Yoshimoto et al., 2018; Hou et al., 2019). ${ }^{\mathbf{5 2 , 5 9}}$ The method is based on first preparing and characterising covalent dendronised polymer (denpol)-enzyme conjugates in bulk aqueous solution. Defined volumes of aqueous solutions of such conjugates at defined enzyme concentrations were then added to the glass fiber filters and incubated for $1 \mathrm{~h}$ at room temperature. Most efficient was the use of $50 \mu \mathrm{L}$ solutions per filter since the entire volume was taken up by the filter through capillary forces. During the incubation, some of the conjugates present in the solution adsorbed on the surface of the fibers through non-covalent interactions. After placement of the filters containing the adsorbed conjugates inside a home-made filter holder, ${ }^{52}$ excess conjugate which did not adsorb and small amounts of free enzyme molecules that might still have been present in the conjugate solution were removed by pumping buffer solution through the filter holder device.

The dendronised polymer used for the preparation of the conjugates was the same as in our previous work, ${ }^{52,59}$ abbreviated as de-PG2 $2_{1000}$ (Fig. 1). It was a deprotected (de) second generation denpol with on average 1000 r.u. per polymer chain and four peripheral amino groups per r.u. The enzyme molecules were connected covalently (via accessible lysine residues) to some of the amino groups along the denpol chains through stable bis-aryl hydrazone (BAH) bonds as linker units. For the work presented here, three conjugates were used, de-PG2 $1000^{-}$ $\mathrm{BAH}_{207}-\mathrm{BCA}_{152}$, de-PG2 ${ }_{1000}-\mathrm{BAH}_{152}-\mathrm{BCA}_{101}$, and de-PG2 $1000^{-}$ $\mathrm{BAH}_{86}-\mathrm{HRP}_{90}$. The subscripts indicate the average numbers of de-PG2 r.u., BAH bonds, and enzyme molecules per de-PG2 chain, as determined experimentally, see Materials and methods. In Fig. 1, the three conjugates are represented in a simplified way by drawing the denpol as stiff cylinder and the enzyme molecules as rigid spheres. Although the real situation is different, the conjugates being flexible structures, ${ }^{21}$ the representation shows, however, that a packing of the enzyme molecules along the denpol chain according to the experimentally determined loading density (average number of enzyme molecules per denpol chain) is spatially feasible and
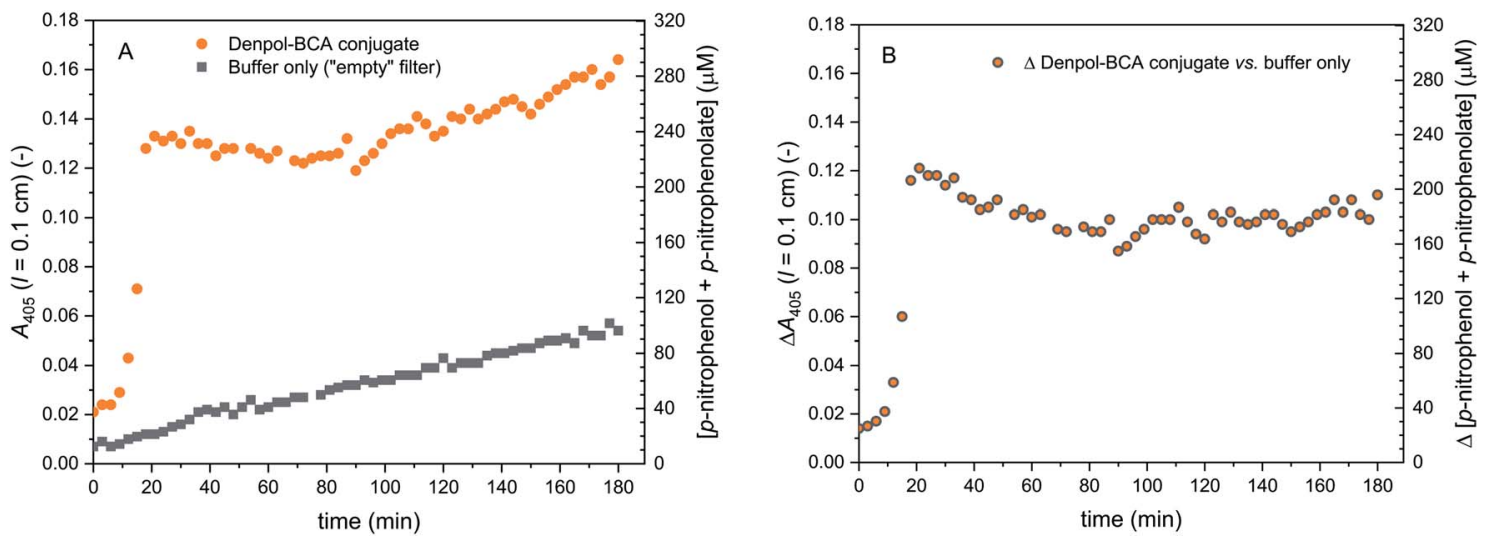

Fig. 9 Activity of de-PG2 $1000-\mathrm{BAH}_{152}-\mathrm{BCA}_{101}$ immobilised in a glass fiber filter, measured with $p$-NA as substrate. The filter was loaded with denpol-BCA conjugate by using $250 \mu \mathrm{L}$ of a conjugate solution (prepared in $\mathrm{PB}, 10 \mathrm{mM}$ sodium phosphate buffer solution, $\mathrm{pH}=7.2$ ) with [BCA] $=$ $2.2 \mu \mathrm{M}$, see Materials and methods and ESI (Section $5 \dagger$ ). The filter was placed inside a filter holder device through which a solution of $1.0 \mathrm{mM} p$-NA (prepared in PB) was pumped through at room temperature at a flow rate of $3 \mu \mathrm{L} \mathrm{min}^{-1}$, and the UV/vis spectrum of the outflow was measured. On the left vertical axes, $A_{405}$ (originating from $p$-nitrophenolate) is plotted vs. time for up to 180 min. (A) Raw data are shown for the reaction with immobilised denpol-BCA conjugate (filled orange circles) and for the background reaction for a filter which did not contain the conjugate (filled black squares). (B) Net formation of $p$-nitrophenolate due to the presence of immobilised BCA (raw data minus background). The total concentration of $p$-nitrophenol $+p$-nitrophenolate is shown on the right vertical axes, see Materials and methods for details. 
that the achieved loading does not appear to be the maximal loading theoretically possible.

The activities of the immobilised conjugates were first determined separately using $p$-NA ( $p$-nitrophenyl acetate) or $\mathrm{ABTS}^{2-} / \mathrm{H}_{2} \mathrm{O}_{2}$ as substrates for filters containing either immobilised de-PG $2_{1000}-\mathrm{BAH}_{152}-\mathrm{BCA}_{101}$ or de-PG2 ${ }_{1000}-\mathrm{BAH}_{86}-\mathrm{HRP}_{90}$. The results are shown in Fig. 9 (for the denpol-BCA conjugate) and Fig. 10 (for the denpol-HRP conjugate). For both conjugates, after an initial equilibration phase of a couple of minutes, the concentrations of the monitored reaction products in the outflow were constant, without any indication of significant enzyme leakage from the filters. Since BCA is not very efficient in catalysing the hydrolysis of $p$-NA, the flow rate in the experiments with immobilised de-PG2 ${ }_{1000}-\mathrm{BAH}_{152}-\mathrm{BCA}_{101}$

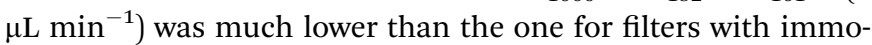
bilised de-PG2 ${ }_{1000}-\mathrm{BAH}_{86}-\mathrm{HRP}_{90}\left(200 \mu \mathrm{L} \mathrm{min}^{-1}\right)$.

The results obtained with the denpol-HRP conjugate showed that stable immobilisation of HRP in glass fiber filters is easily possible, as in the case of the denpol-BCA conjugate. ${ }^{52}$ Furthermore, if an excess volume of the denpol-HRP solution $(250 \mu \mathrm{L})$ was added to a filter so that the maximum volume that could be taken up by the filter $(50 \mu \mathrm{L})$ was exceeded, the product concentrations in the filter outflow were very similar to the ones obtained by loading with $50 \mu \mathrm{L}$. This indicates that efficient enzyme loading can be achieved with a minimum volume of conjugate (e.g. for the used amount: $50 \mu \mathrm{L} \times 0.5 \mu \mathrm{M}=25 \mathrm{pmol}$ active HRP in conjugated form per filter, see Materials and methods).

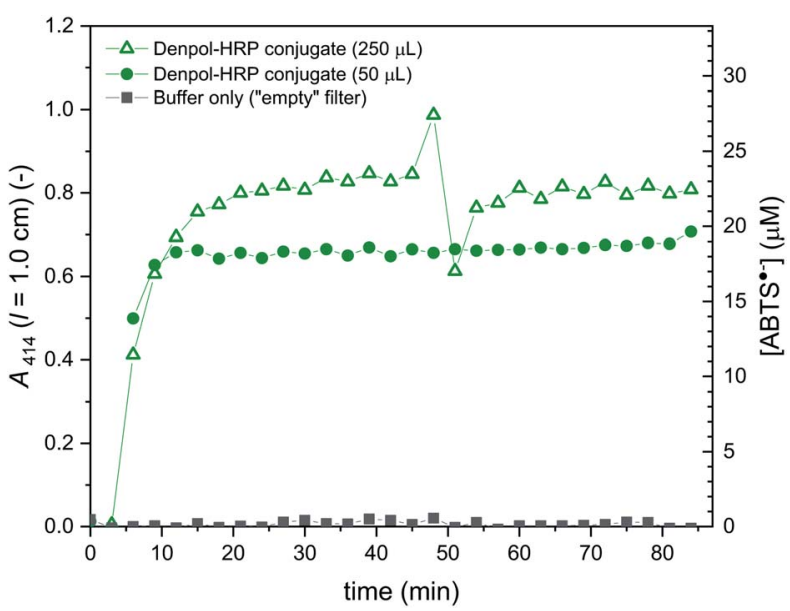

Fig. 10 Activity of de-PG2 ${ }_{1000}-\mathrm{BAH}_{86}-\mathrm{HRP}_{90}$ immobilised in a glass fiber filter, measured with $A B T S^{2-} / \mathrm{H}_{2} \mathrm{O}_{2}$ as substrates. The filter was loaded with denpol-HRP conjugate by using either 50 (filled circles) or $250 \mu \mathrm{L}$ (empty triangles) of the conjugate solution (prepared in $10 \mathrm{mM}$ sodium phosphate buffer, $[\mathrm{NaCl}]=0.15 \mathrm{M}, \mathrm{pH}=7.0$ ) with $[\mathrm{HRP}]=0.5$ $\mu \mathrm{M}$, see Materials and methods. The filter was placed in a filter holder device through which a solution of $1.0 \mathrm{mM} \mathrm{ABTS}^{2-}$ and $0.2 \mathrm{mM} \mathrm{H}_{2} \mathrm{O}_{2}$ was pumped at room temperature at a flow rate of $200 \mu \mathrm{L} \mathrm{min}^{-1}$, and the UV/vis spectrum of the outflow was measured. On the left axis, $A_{414}$ originating from $\mathrm{ABTS}^{-{ }^{-}}$is plotted vs. time up to $84 \mathrm{~min}$. The calculated concentration of ABTS ${ }^{--}$in the outflow is given on the right vertical axis. Data for glass fiber filters which did not contain the conjugate (at a flow rate of $40 \mu \mathrm{L} \mathrm{min}{ }^{-1}$ ) are also shown (filled squares). The scattering of the data around 50 min (empty triangles) was caused by an air bubble passing the filter holder.
In addition to the immobilisation of the two enzymes in separate filters, stable co-immobilisation of both enzymes in one and the same filter was also shown to be equally simple by incubation of $50 \mu \mathrm{L}$ of an aqueous solution prepared from stock solutions of both conjugates, see Materials and methods.

\subsection{Cascade reaction of $\mathrm{DCFH}_{2}$-DA and $\mathrm{H}_{2} \mathrm{O}_{2}$ in a flow- through device with BCA and HRP immobilised in glass fiber filters}

The same cascade reaction, which we first investigated in bulk solution with dissolved, free BCA and HRP added at the beginning of the reaction, was used for gaining information about the performance of the two enzymes when they were immobilised in glass fiber filters and used in a flow-through device. Different types of experiments were carried out, as illustrated in Fig. 11. In all cases, the outflow from the filters was analysed by recording the absorption spectrum between $\lambda=$ 240 and $600 \mathrm{~nm}$. The spectral region in which only the oxidised species absorb $(\lambda=330-600 \mathrm{~nm})$ is shown in Fig. S-22, ESI. $\dagger$

In Fig. $12, A_{503} v s$. the time the substrate solution consisting of DCFH $_{2}$-DA $(50 \mu \mathrm{M})$ and $\mathrm{H}_{2} \mathrm{O}_{2}(9 \mu \mathrm{M})$ in $\mathrm{PB}(\mathrm{pH}=7.2)$ was pumped through the filter holder device is shown for the cascade reaction with both enzymes co-immobilised in the same filter (1) in Fig. 11, left hand side) and with sequentially immobilised enzymes (1) in Fig. 11, right hand side: BCA first, HRP second). The DCF concentration in the outflow was calculated by assuming insignificant $\mathbf{D C F}_{\mathbf{o x}}$ formation (which was shown to be a reasonable assumption, see below). For both arrangements, two independent experiments were carried out, see the legend of Fig. 12. The trend was in both sets of experiments the same: $A_{503}$ for the co-immobilised enzymes was about $50 \%$ higher than $A_{503}$ for the sequentially immobilised enzymes. This clearly indicates larger amounts of DCF formed for the co-immobilised enzymes $(\approx 1.5 \mu \mathrm{M})$ as compared to the sequentially immobilised enzymes $(\approx 0.9 \mu \mathrm{M})$. Analysis of the UV/vis spectra of the outflow between $\lambda=330$ and $600 \mathrm{~nm}$ by spectral fitting, using the reference spectra shown in Fig. 2, showed, however, that for both arrangements (co-immobilised and sequentially immobilised) the total concentration [DCF $]+$ [DCF-MA] was the same, see Fig. 13 and S-23, ESI. $\dagger$ The only difference was the ratio of the two products: $59 \%$ DCF with the co-immobilised enzymes, 39\% DCF with the sequentially immobilised enzymes. In both cases, the "oxidation turnover" was the same $\left(\approx 1.2-1.3 \mu \mathrm{M} \mathrm{H}_{2} \mathrm{O}_{2}\right.$ out of the $9 \mu \mathrm{M}$ present in the substrate solution which was pumped through the filters were "consumed" by the dichlorofluorescein derivative), indicating for both cases a similar amount of immobilized HRP. Moreover, no proximity or channeling effects were effective due to a coimmobilisation of the two enzymes, as this should speed up the oxidation as second reaction step. Of course the oxidation could theoretically only be speeded up by proximity or channeling effects, if oxidation would be a rate limiting step. In both cases (sequentially- and co-immobilized enzymes), no significant amounts of overoxidised products (no $\mathbf{D C F}_{\mathbf{o x}}$ ) were present in the outflow. Indeed, this identifies the oxidation reaction as a rate limiting step for the total amount of DCF-MA + DCF (while 


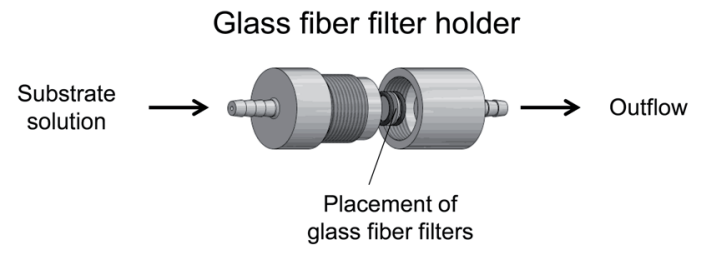

Cascade reactions

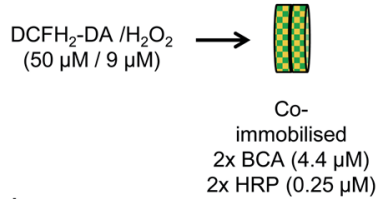

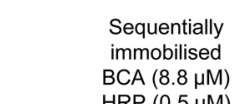

Controls

$$
\underset{(1 \mathrm{mM})}{p-\mathrm{NA}} \longrightarrow \underset{\text { Empty }}{\prod}
$$

(3)

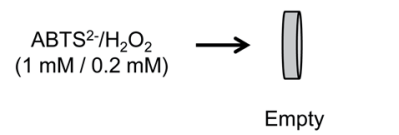

or

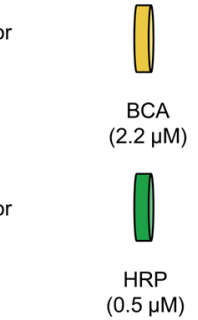

(4)

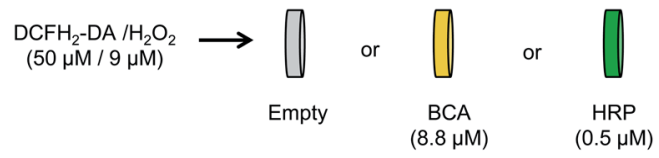

(5)

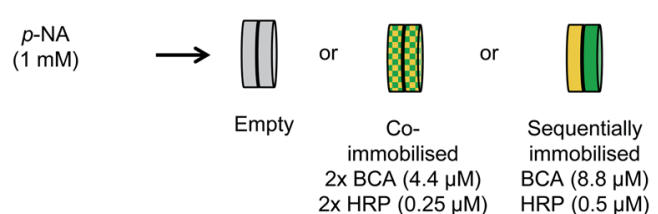

Fig. 11 Illustration of the two setups used for the cascade reaction in a flow-through device consisting of glass fiber filters with immobilised denpol-BCA conjugate (yellow) and denpol-HRP conjugate (green) (1)), and for the different control measurements carried out (2) - (5)). All filters were loaded with $50 \mu \mathrm{L}$ of the corresponding denpol-enzyme conjugate solutions or with $50 \mu \mathrm{L}$ PB solution ( $\mathrm{pH}=7.2$, "empty" filters). The enzyme concentrations in the conjugate solutions used for loading the filters are given in parenthesis; all filters were placed in the home-made filter holder ${ }^{52}$ and kept at room temperature; see Materials and methods. (1): Cascade reaction with co-immobilised BCA and HRP or with sequentially immobilised BCA (first) and HRP (second), analysed by using a PB solution containing $50 \mu \mathrm{M} \mathrm{DCFH}$-DA $^{-D} 9 \mu \mathrm{M}$ $\mathrm{H}_{2} \mathrm{O}_{2}$ as substrates. (2): Control measurements with an "empty" filter or with a filter containing immobilised BCA, using $1 \mathrm{mM} p-\mathrm{NA}$ in $\mathrm{PB}$ as substrate. (3): Control measurements with an "empty" filter or with a filter containing immobilised HRP, using $1 \mathrm{mM} \mathrm{ABTS}^{2-}$ and $0.2 \mathrm{mM}$ $\mathrm{H}_{2} \mathrm{O}_{2}$ as substrates. (4) Control measurements with an "empty" filter or with a filter containing either immobilised BCA or HRP, using $50 \mu \mathrm{M}$ DCFH $H_{2}$-DA and $9 \mu \mathrm{M} \mathrm{H}_{2} \mathrm{O}_{2}$ as substrates. (5): Control measurements with two "empty" filters or with two filters containing either coimmobilised BCA and HRP or sequentially immobilised BCA (first) and HRP (second), using $1 \mathrm{mM} p-\mathrm{NA}$ in PB as substrate.

the hydrolysis reaction, i.e. BCA, was limiting the relative amount of DCF within the oxidised species DCF-MA + DCF).

Consequently, the reason for the difference in the amount of DCF formed in the two setups is not a different oxidation

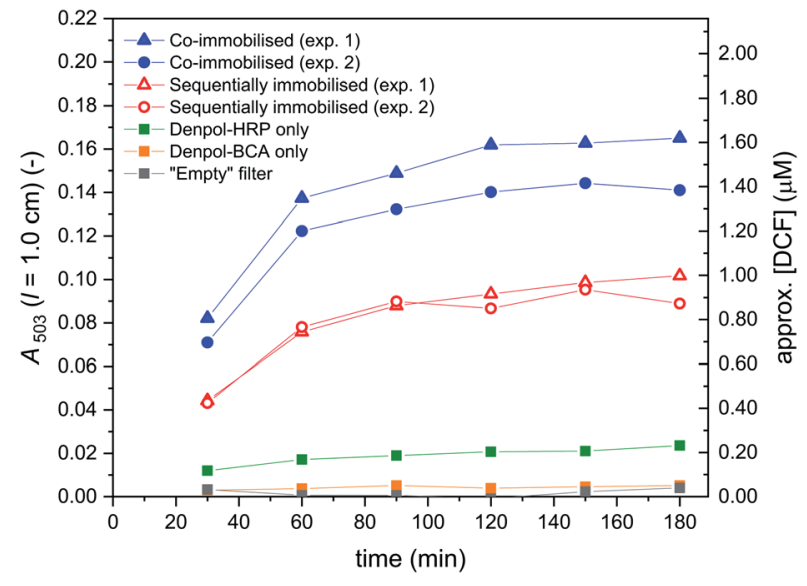

Fig. 12 Cascade reaction in a flow-through device consisting of glass fiber filters with immobilised de-PG2 ${ }_{1000}-\mathrm{BAH}_{207}-\mathrm{BCA}_{152}$ and de$P G 2_{1000}-\mathrm{BAH}_{86}-\mathrm{HRP}_{90}$ (1) in Fig. 11). The conjugates were immobilised by adding to each filter a volume of $50 \mu \mathrm{L}$ of the denpol-enzyme conjugate solutions at the enzyme concentrations indicated in Fig. 11. Filled blue symbols: data for co-immobilised denpol-enzyme conjugates (two independent immobilisations and analyses). Empty red symbols: data for sequentially immobilised denpol-enzyme conjugates (denpol-BCA first, denpol-HRP second; two independent immobilisations and analyses). The performance of the immobilised enzymes was carried out by pumping a solution consisting of $50 \mu \mathrm{M}$ $\mathrm{DCFH}_{2}$-DA and $9 \mu \mathrm{M} \mathrm{H}_{2} \mathrm{O}_{2}$ in $\mathrm{PB}(\mathrm{pH}=7.2)$ through the filter holder device at $5 \mu \mathrm{L} \mathrm{min}{ }^{-1}$. The outflow was collected in portions of $150 \mu \mathrm{L}$ in polypropylene tubes (collection for $30 \mathrm{~min}$ ), followed by immediate measurement of the UV/vis absorption spectrum (Fig. S-22, ESI†). $A_{503}$ is plotted against the time the substrate solution was pumped through the filters. Control measurements with either an "empty" filter, a filter containing immobilised denpol-BCA only, or a filter containing immobilised denpol-HRP only, were carried out according to (4) in Fig. 11.

turnover (as already mentioned above), but a different extent of hydrolysis within the total amount of oxidised compounds (DCF-MA + DCF). This altered hydrolysis extent was caused by the different arrangement of the two enzymes. In the sequential immobilisation, BCA-catalysed hydrolysis reactions only take place before oxidations, disabling Hyd_3 in Scheme 2. Therefore, any compounds being oxidized according to pathway 2 will ultimately end up as DCF-MA and thus, formation of DCF is only possible via pathway 1 (Scheme 2). For the co-immobilised enzymes, BCA-catalysed hydrolysis and HRP-catalysed oxidation reactions are possible from the very beginning, allowing DCF formation to proceed along pathway 1 and pathway 2 (Scheme 2). For the sequential setup, the molar ratio of final DCF-MA to final DCF is predetermined by the molar ratio of $\mathbf{D C F H} \mathbf{H}_{2}-\mathbf{M A}$ to $\mathbf{D C F H} \mathbf{C}_{2}$ (thus by Hyd_2) when leaving the first filter containing immobilised BCA. ${ }^{73}$ Since in the co-immobilised setup, hydrolysis is possible before and after oxidation, the molar ratio of final DCF-MA to final DCF is determined by both, Hyd_2 and the more efficient Hyd_3 (Scheme 2). To sum up: the DCF to DCFMA ratio in the sequential immobilisation was lower as only the less efficient hydrolysis of $\mathbf{D C F} \mathbf{H}_{\mathbf{2}}$-MA (Hyd_2) was determining it since the more efficient hydrolysis of DCF-MA (Hyd_3) was disabled. In contrast, for co-immobilised enzymes this ratio was 


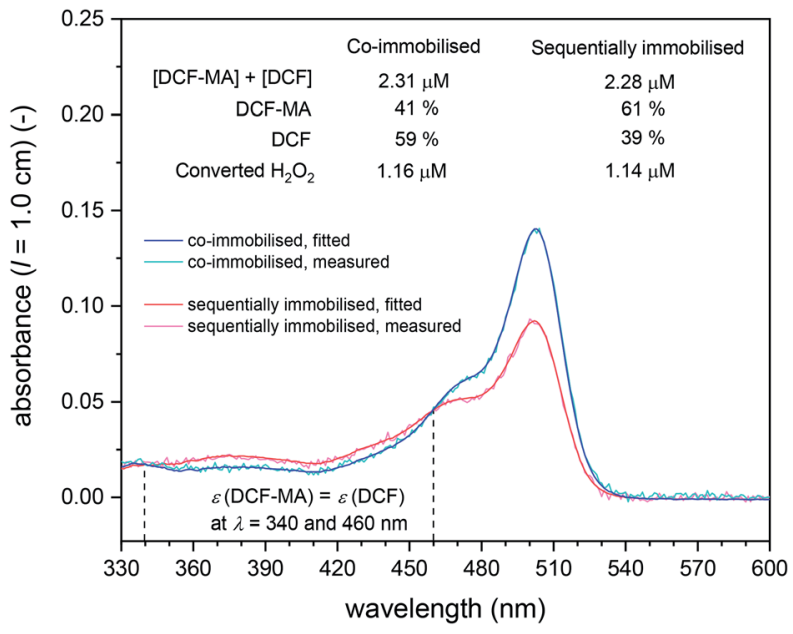

Fig. $13 U$ UV/vis absorption spectra between $\lambda=330$ and $600 \mathrm{~nm}$ of the outflow from the filter holder device for cascade reactions (1) in Fig. 11 for co-immobilised (blue) and sequentially immobilised conjugates (red), collected between $t=150$ and $180 \mathrm{~min}$ ("exp. 2", blue filled circle and red empty circle at $t=180 \mathrm{~min}$ in Fig. 12). The measured and fitted spectra are shown with the total concentrations of DCF-MA and DCF and the relative amounts of DCF-MA and DCF present in the outflow. The spectra fitting was done as described for the analysis of the reaction run in bulk solution (see caption of Table S-3, ESI†).

determined by both hydrolysis reactions (both at the same time, as for simultaneously present enzymes in bulk solution). The extent of oxidation ([DCF $]+[$ DCF-MA $])$, however, was the same in both setups.

The results of the control measurements (4) illustrated in Fig. 11 are shown in Fig. 12: $A_{503}$ in the outflow remained low, as expected from the Controls 1, 2, and 4 made in bulk solution, see Fig. S-10, S-11, and S-14, ESI. $\dagger$
As mentioned, different DCF to DCF-MA molar ratios in the outflows were observed for the two different setups (coimmobilised and sequentially immobilized enzymes). Besides from different enzyme arrangements, the extent of hydrolysis is also dependent on the amount of immobilised BCA. In order to prove that the differences in the DCF to DCF-MA ratio for the two setups originated from a disabled hydrolysis of DCF-MA in the case of the sequentially immobilised enzymes and not from different amounts of immobilised BCA, control measurements (5) of Fig. 11 were carried out. BCA and HRP were again immobilised in glass fiber filters in the two different setups and placed in the filter holder. A $1 \mathrm{mM} p$-NA solution in $\mathrm{PB}(\mathrm{pH}=$ 7.2) was then pumped through the two devices at the same flow rate and the outflow was analysed by measuring $A_{405}$ (indicative for the formation of $p$-nitrophenolate) see Fig. 14. The two measurements gave identical $A_{405} v s$. time profiles, indicating that in both setups, the same amounts of active BCA were immobilised.

\section{Conclusions}

The enzymatic conversion of $\mathbf{D C F H}_{\mathbf{2}}$-DA into DCF, catalysed by BCA and $\mathrm{HRP} / \mathrm{H}_{2} \mathrm{O}_{2}$, is a complex example of a two-enzyme cascade reaction. It is complex because two reaction pathways exist, involving five different reactions steps (Scheme 2). Moreover, under certain conditions the final product, DCF, may be further oxidised to $\mathbf{D C F}_{\mathbf{o x}}$ (Scheme 1). Nevertheless, the reaction turned out to be an interesting model reaction that could be tuned and analysed in bulk solution by simple time-dependent $\mathrm{UV} / \mathrm{vis}$ absorption measurements. The determination of the spectra of all components of the reaction (Fig. 2 and S-6, ESI $\dagger$ ) and of the molar absorption coefficients of isosbestic points (Table 1) was crucial for understanding the changes in the absorption spectrum of the reaction mixture during the
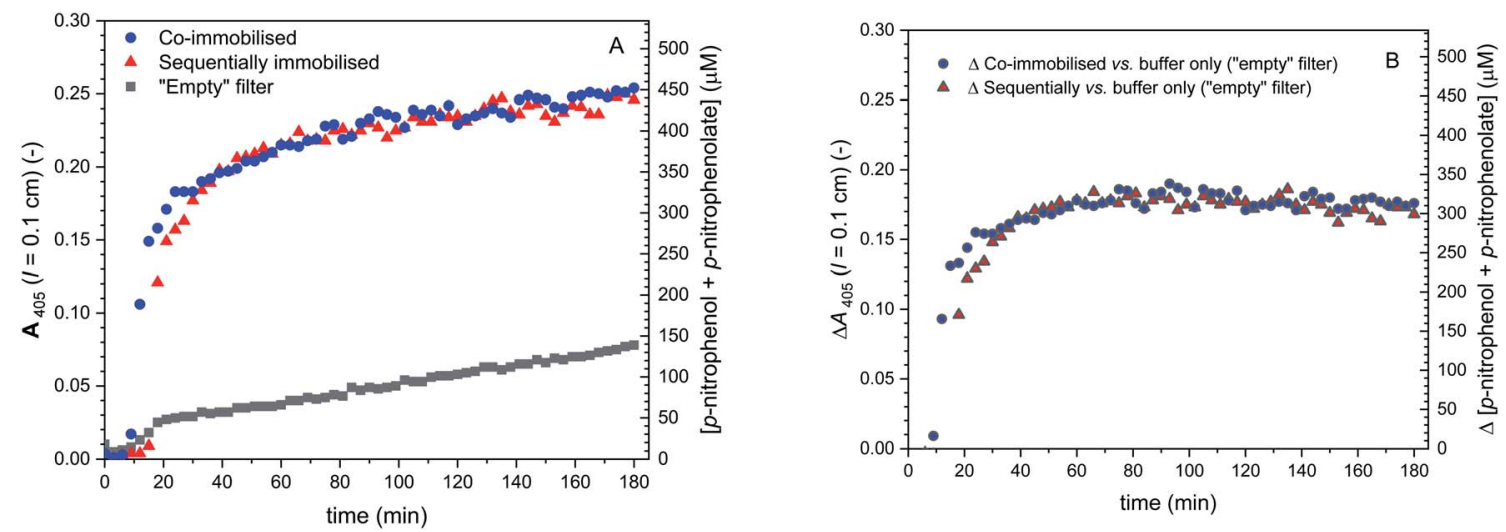

Fig. 14 Activity of de-PG2 $1000-\mathrm{BAH}_{207}-\mathrm{BCA}_{152}$ immobilised in glass fiber filters placed in a flow-through device, either together with de$\mathrm{PG} 2_{1000}-\mathrm{BAH}_{86}-\mathrm{HRP}_{90}$ (blue symbols, two filters, co-immobilised) or sequentially with de-PG2 $1000-\mathrm{BAH}_{86}-\mathrm{HRP}_{90}$ in the second filter (red symbols, two filters, sequentially immobilised), measured with $p$-NA as substrate (experiments (5) in Fig. 11). The conjugates were immobilised by adding to each filter a volume of $50 \mu \mathrm{L}$ of the denpol-enzyme conjugate solutions at the concentrations indicated in Fig. 11. A solution of $1 \mathrm{mM} p-$ $\mathrm{NA}$ prepared in $\mathrm{PB}(\mathrm{pH}=7.2)$ was pumped through the filter device at $3 \mu \mathrm{L} \mathrm{min}^{-1}$. The outflow was analysed by measuring $A_{405}$ (left vertical axes), from which the total concentrations of $p$-nitrophenolate $+p$-nitrophenol was calculated (right vertical axes), see Materials and methods. Data for background measurements with two "empty" filters are also shown (non-enzymatic $p$-NA hydrolysis). (A) Raw data. (B) Net formation of $p$ nitrophenolate and calculated total concentration of $p$-nitrophenolate $+p$-nitrophenol, due to the presence of BCA (raw data minus background). For both setups, the same outflow resulted, indicating identical BCA activity, i.e. identical denpol-BCA conjugate loading. 
reaction. This detailed analysis in bulk solution was then the basis for analysing the outflow from a flow-through device containing glass fiber filters with immobilised BCA and HRP. Although the arrangement with co-immobilised BCA and HRP resulted in a higher yield of DCF as compared to sequentially immobilised enzymes (BCA first, HRP second), this higher yield was not due to a proximity effect. It is simply a consequence of the fact that the transformation of $\mathbf{D C F H}_{2}$-DA into DCF can occur via two possible pathways (Scheme 2). One pathway becomes "interrupted" halfway in the sequential arrangement (no hydrolysis after oxidation possible anymore, disabling one hydrolysis step), while both of them are still fully available for DCF formation when using co-immobilised enzymes (as for simultaneously added enzymes in bulk solution). Through which of the two pathways the reaction can proceed to the final product (DCF) thus depends on the arrangement of the enzymes. Through which of the two pathways the reaction will proceed to what extent depends on the amounts, i.e., the activities of the enzymes as well as the reaction time (the lower the HRP to BCA ratio, the higher the contribution from pathway 1 ; and the lower the reaction time, the higher the contribution from pathway 2, see Scheme 2).

Concerning the methodology used for the immobilisation of the two enzymes in glass fiber filters, the previously developed protocol for $\mathrm{BCA}^{52}$ was slightly modified in terms of the amount of denpol-BCA conjugate solution added to the filter (actual immobilisation step via simple conjugate adsorption from aqueous solution) and in terms of the washing procedure. For HRP, stable immobilisation in the filters was successful following the procedure previously elaborated for immobilising the enzyme inside mesoporous silicate monoliths. ${ }^{59}$ Simple coimmobilisation was possible by solely mixing two different enzyme conjugate solutions in defined amounts before incubation in one and the same filter (showing similar activities as for individual immobilisations with the same stock solutions, see Fig. 14). This study confirms that the enzyme immobilisation methodology which we are being developing since a few years ${ }^{21,58,59,74,75}$ is a valuable alternative to the more conventional methods. ${ }^{2,76-78}$

\section{Conflicts of interest}

There are no conflicts of interest to declare.

\section{Acknowledgements}

The authors thank the Swiss National Science Foundation (200021_175440) for financial support, Dr Daniel Messmer and Prof. A. Dieter Schlüter (D-MATL, ETH) for providing dendronised polymer, Dr Thomas Schweizer (D-MATL, ETH) for the fabrication of the glass fiber filter holder device, Dr Martin Willeke (D-MATL, ETH), Dr Reinhard Kissner and Dr Thomas Nauser (both D-CHAB, ETH) for discussions about the cascade reaction. K. S. acknowledges the Innovative Flex Course for Frontier Organic Material Systems (iFront) of Yamagata University (YU) for financial support for the research collaboration between YU and ETH. M. Y. acknowledges the Japan
Society for the Promotion of Science (JSPS) KAKENHI grant number 15KK0241 for financial support. S. P.-E. thanks the Ministry of Science, Research and Technology of the Islamic Republic of Iran for the scholarship for staying at ETH (grant number 661026). P. S. is grateful to Prof. Sandra Incerpi (University Roma Tre) for discussions about $\mathbf{D C F H}_{\mathbf{2}}$-DA.

\section{Notes and references}

1 I. Wheeldon, S. D. Minteer, S. Banta, S. C. Barton, P. Atanassov and M. Sigman, Nat. Chem., 2016, 8, 299-309.

2 A. Küchler, M. Yoshimoto, S. Luginbühl, F. Mavelli and P. Walde, Nat. Nanotechnol., 2016, 11, 409-420.

3 P. Gruber, M. P. C. Marques, B. O'Sullivan, F. Baganz, R. Wohlgemuth and N. Szita, Biotechnol. J., 2017, 12, 1700030.

4 K. Meller, M. Szumski and B. Buszewski, Sens. Actuators, B, 2017, 244, 84-106.

5 M. B. Quin, K. K. Wallin, G. Zhang and C. Schmidt-Dannert, Org. Biomol. Chem., 2017, 15, 4260-4271.

6 S. P. France, L. J. Hepworth, N. J. Turner and S. L. Flitsch, ACS Catal., 2017, 7, 710-724.

7 Y. Zhang and H. Hess, ACS Catal., 2017, 7, 6018-6027.

8 J. Britton, S. Majumdar and G. A. Weiss, Chem. Soc. Rev., 2018, 47, 5891-5918.

9 G. Zhang, M. B. Quin and C. Schmidt-Dannert, ACS Catal., 2018, 8, 5611-5620.

$10 \mathrm{~S}$. Velasco-Lozano and F. López-Gallego, Biocatal. Biotransform., 2018, 36, 184-194.

11 J. Yin, S. Chen, N. Zhang and H. Wang, ACS Appl. Mater. Interfaces, 2018, 10, 21883-21890.

12 J. Shi, Y. Wu, S. Zhang, Y. Tian, D. Yang and Z. Jiang, Chem. Soc. Rev., 2018, 47, 4295-4313.

13 K. Vogele, J. List, F. C. Simmel and T. Pirzer, Langmuir, 2018, 34, 14780-14786.

14 F. S. Aalbers and M. W. Fraaije, ChemBioChem, 2019, 20, 2028.

15 S. Tsikov and H. Hess, ACS Catal., 2019, 9, 2432-2439.

16 E. T. Hwang and S. Lee, ACS Catal., 2019, 9, 4402-4425.

17 Z. Chen, H. Cao and T. Tan, New J. Chem., 2019, 43, 85178526.

18 A. Kuzmak, S. Carmali, E. von Lieres, A. J. Russell and S. Kondrat, Sci. Rep., 2019, 9, 455.

19 Y. Cao, X. Li, J. Xiong, L. Wang, L.-T. Yan and J. Ge, Nanoscale, 2019, 11, 22108-22117.

20 S. Fornera, T. Bauer, A. D. Schlüter and P. Walde, J. Mater. Chem., 2012, 22, 502-511.

21 A. Küchler, J. Adamcik, R. Mezzenga, A. D. Schlüter and P. Walde, RSC Adv., 2015, 5, 44530-44544.

22 S. Fornera, K. Yazawa and P. Walde, Anal. Bioanal. Chem., 2011, 401, 2307-2310.

23 R. E. Childs and W. G. Bardsley, Biochem. J., 1975, 145, 93103.

24 P. D. Josephy, T. Eling and R. P. Mason, J. Biol. Chem., 1982, 257, 3669-3675.

25 S. Fornera and P. Walde, Anal. Biochem., 2010, 407, 293-295. 26 A. S. Keston and R. Brandt, Anal. Biochem., 1965, 11, 1-5. 
27 C. P. LeBel, H. Ischiropoulos and S. C. Bondy, Chem. Res. Toxicol., 1992, 5, 227-231.

28 J. P. Crow, Nitric Oxide, 1997, 1, 145-157.

29 M. M. Tarpey and I. Fridovich, Circ. Res., 2001, 89, 224-236.

30 J. Glebska and H. W. Koppenol, Free Radical Biol. Med., 2003, 35, 676-682.

31 P. Wardman, Free Radical Biol. Med., 2007, 43, 995-1022.

32 X. Chen, Z. Zhong, Z. Xu, L. Chen and Y. Wang, Free Radical Res., 2010, 44, 587-604.

33 B. Kalayanaraman, V. Darley-Usmar, K. J. A. Davies, P. A. Dennery, H. J. Forman, M. B. Grisham, G. E. Mann, K. Moore, L. J. Roberts II and H. Ischiropoulos, Free Radical Biol. Med., 2012, 52, 1-6.

34 V. Balducci, S. Incerpi, P. Stano and D. Tofani, Biochim. Biophys. Acta, Biomembr., 2018, 1869, 600-610.

35 J. D. Cohen and H. D. Husic, Phytochem. Anal., 1991, 2, 6064.

36 E. D'Aguanno, E. Altamura, F. Mavelli, A. Fahr, P. Stano and P. L. Luisi, Life, 2015, 5, 969-996.

37 H. Leonhardt, L. Gordon and R. Livingston, J. Phys. Chem., 1971, 75, 245-249.

38 N. O. Mchedlov-Petrossyan, M. I. Rubtsov and L. L. Lukatskaya, Dyes Pigm., 1992, 18, 179-198.

39 C. Rota, Y. C. Fann and R. P. Mason, J. Biol. Chem., 1999, 274, 28161-28168.

40 Variations of this type of two-enzyme cascade reaction according to pathway 1 are well known from literature and often applied as qualitative assay $^{29}$ for detecting the presence of certain reactive oxygen or reactive nitrogen species (ROS or RNS, e.g. hydroxyl radicals, $\mathrm{HO}^{\circ}$, or nitrogen dioxide radicals, $\left.\mathrm{NO}_{2}^{\cdot}\right)^{28,30,31}$ inside biological cells. $^{32,33}$ The principle is the following. If added to biological cells, lipophilic $\mathbf{D C F H}_{2}$-DA permeates across the cell membrane. ${ }^{32}$ Inside the cells, the hydrolysis of $\mathbf{D C F H}_{2}$ DA is catalysed by intracellular esterases, and the formed membrane-impermeable $\mathbf{D C F H}_{2}$ reacts non-specifically with ROS or RNS to yield DCF. ${ }^{\mathbf{3 1 , 3 2}}$ According to literature, $\mathrm{H}_{2} \mathrm{O}_{2}$ alone cannot directly oxidise $\mathbf{D C F H}_{2}{ }^{32,41,42}$ while $\mathbf{D C F H}_{2}$ oxidation in aerobic aqueous solution containing $\mathrm{H}_{2} \mathrm{O}_{2}$ occurs with peroxidases like HRP. ${ }^{31,41}$ In our investigations, BCA was used as "esterase" and $\mathrm{HRP} / \mathrm{H}_{2} \mathrm{O}_{2}$ and dissolved $\mathrm{O}_{2}$ as oxidants.

41 H. Ischiropoulos, A. Gow, S. R. Thom, N. W. Kooy, J. A. Royall and J. P. Crow, Methods Enzymol., 1999, 301, 367-373.

42 M. B. Grisham, Comp. Biochem. Physiol., Part A: Mol. Integr. Physiol., 2013, 165, 429-438.

43 C. F. Chignell and R. H. Sik, Free Radical Biol. Med., 2003, 34, 1029-1034.

44 C. Rota, C. F. Chignell and R. P. Mason, Free Radical Biol. Med., 1999, 27, 873-881.

45 N. C. Veitch and A. T. Smith, Adv. Inorg. Chem., 2001, 51, 107162.

46 G. I. Berglund, G. H. Carlsson, A. T. Smith, H. Szöke, A. Henriksen and J. Hajdu, Nature, 2002, 417, 463-468.

47 H. B. Dunford, Peroxidases \& Catalases: Biochemistry, Biotechnology, and Physiology, John Wiley \& Sons, 2nd edn, 2010, ch. 3, pp. 13-39.
48 M. Wrona and P. Wardman, Free Radical Biol. Med., 2006, 41, 657-667.

49 E. Marchesi, C. Rota, Y. C. Fann, C. F. Chignell and R. R. Mason, Free Radical Biol. Med., 1999, 26, 148-161.

50 B. H. J. Bielski and A. O. Allen, J. Phys. Chem., 1977, 81, 10481050.

51 M. Li, L. Liu, Y. Shi, Y. Yang, H. Zheng and Y. Long, New J. Chem., 2017, 41, 7578-7582.

52 M. Yoshimoto, T. Schweizer, M. Rathlef, T. Pleij and P. Walde, ACS Omega, 2018, 3, 10391-10405.

53 R. Saito, T. Sato, A. Ikai and N. Tanaka, Acta Crystallogr., Sect. D: Biol. Crystallogr., 2004, 60, 792-795.

54 V. M. Krishnamurthy, G. K. Kaufman, A. R. Urbach, I. Gitlin, K. L. Gudiksen, D. B. Weibel and G. M. Whitesides, Chem. Rev., 2008, 108, 946-1051.

55 S. Lindskog, Biochim. Biophys. Acta, 1960, 39, 218-226.

56 H. B. Dunford and J. S. Stillman, Coord. Chem. Rev., 1976, 19, 187-251.

57 S. Aibara, H. Yamashita, E. Mori, M. Kato and Y. Morita, J. Biochem., 1982, 92, 531-539.

58 A. Küchler, D. Messmer, A. D. Schlüter and P. Walde, Methods Enzymol., 2017, 590, 445-474.

59 C. Hou, N. Ghéczy, D. Messmer, K. Szymańska, J. Adamcik, R. Mezzenga, A. B. Jarzębski and P. Walde, ACS Omega, 2019, 4, 7795-7806.

60 R. W. Noble and Q. H. Gibson, J. Biol. Chem., 1970, 245, 2409-2413.

61 A. Innocenti, A. Scozzafava, S. Parkkila, L. Puccetti, G. De Simone and C. T. Supuran, Bioorg. Med. Chem. Lett., 2008, 18, 2267-2271.

62 H. B. Dunford, Peroxidases and Catalases: Biochemistry, Biotechnology, and Physiology, John Wiley \& Sons, 2nd edn, 2010, ch. 4, pp. 41-56.

63 P. Campomanes, U. Rothlisberger, M. Alfonso-Prieto and C. Rovira, J. Am. Chem. Soc., 2015, 137, 11170-11178.

64 M. J. Reiniers, R. F. van Golen, S. Bonnet, M. Broeckgaarden, T. M. van Gulik, M. R. Egmond and M. Heger, Anal. Chem., 2017, 89, 3853-3857.

65 J. Hofmann and M. Sernetz, Anal. Biochem., 1983, 131, 180186.

66 F. Fiedler and H. Hinz, Eur. J. Biochem., 1994, 222, 75-81.

67 B. H. J. Bielski, D. E. Cabelli, R. L. Arudi and A. B. Ross, J. Phys. Chem. Ref. Data, 1985, 14, 1041-1100.

68 I. B. Afanas'ev, Superoxide Ion Chemistry and Biological Implications, CRC Press, Boca Raton, FL, 1st edn, 1991, ch. 5, vol. II, pp. 135-205.

69 M. Hayyan, M. A. Hashim and I. M. AlNashef, Chem. Rev., 2016, 116, 3029-3085.

70 The fact that a stable absorption spectrum was reached indicates that $\mathbf{D C F H} \mathbf{H}_{2}$ was not oxidised without $\mathrm{H}_{2} \mathrm{O}_{2}$ under the conditions used during the experiments. The absorption peak at $\lambda=287 \mathrm{~nm}$ originating from $\mathbf{D C F H}_{2}$ remained unaltered between $t=15$ and $19 \mathrm{~min}$, see Fig. S20B, ESI. $\dagger$

71 For transient $\left[\mathrm{H}_{2} \mathrm{O}_{2}\right]>\left[\mathbf{D C F H}_{2}\right]$, an additional condition for DCF overoxidation is that HRP is not completely "occupied" with the kinetically favored oxidation of $\mathbf{D C F H}_{2}$ 
until the transient condition $\left[\mathrm{H}_{2} \mathrm{O}_{2}\right]>\left[\mathbf{D C F H}_{2}\right]$ is not met anymore. This additional condition is not valid anymore for low HRP concentrations in the cascade reaction (see 3.1.6.).

72 Hydrolysis of DCF-MA can also be seen from the decrease in $A_{370}$. At $\lambda=370 \mathrm{~nm}$, DCF does not absorb significantly, see Fig. 2B.

73 Of ocurse this is only valid as long as the hydrolysis of DCFH 2 -MA to $\mathbf{D C F H} \mathbf{F}_{2}$ was not yet complete in the solution leaving the first filter. Such incomplete hydrolysis was confirmed by the presence of DCF-MA in the filter outflow.
74 S. Fornera, P. Kuhn, D. Lombardi, A. D. Schlüter, P. S. Dittrich and P. Walde, ChemPlusChem, 2012, 77, 98-101.

75 A. Küchler, J. N. Bleich, B. Sebastian, P. S. Dittrich and P. Walde, ACS Appl. Mater. Interfaces, 2015, 7, 25970-25980.

76 R. A. Sheldon and S. van Pelt, Chem. Soc. Rev., 2013, 42, 6223-6235.

77 S. B. Sigurdardóttir, J. Lehmann, S. Ovtar, J.-C. Grivel, M. Della Negra, A. Kaiser and M. Pinelo, Adv. Synth. Catal., 2018, 360, 2578-2607.

78 Y.-K. Cen, Y.-X. Liu, Y.-P. Xue and Y.-G. Zheng, Adv. Synth. Catal., 2019, 361, 5500-5515. 